\title{
Laser Shock Processing as an Advanced Technique for the Surface and Mechanical Resistance Properties Modification of Bioabsorbable Magnesium Alloys
}

J.L. Ocaña ${ }^{1}$, J.L. González-Carrasco ${ }^{2,3}$, M. Lieblich ${ }^{2}$, J.C. Galván² J.A. Porro ${ }^{1}$, M. Díaz ${ }^{1}$, F. Cordovilla ${ }^{1}$, I. Angulo ${ }^{1}$, I. Izaguirre².

${ }^{1}$ UPM Laser Center. Polytechnical University of Madrid. Ctra. Valencia, km. 7.3. 28031 Madrid. Spain

${ }^{2}$ National Center for Metallurgical Research (CENIM-CSIC), Avda Gregorio del Amo, 8. 28040 Madrid. Spain

${ }^{3}$ Center for Networked Research on Bioengineering, Biomaterials and Nanomedicine. Spain

$$
\text { e-mail: jlocana@etsii.upm.es }
$$

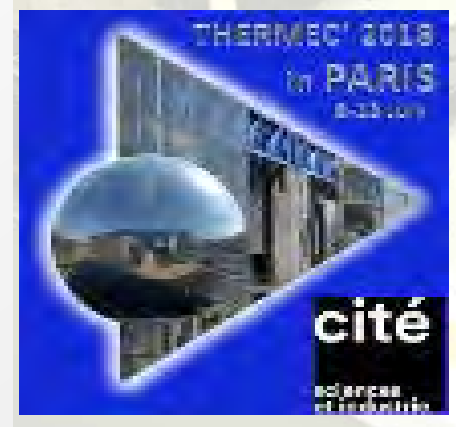

International Conference on

PROCESSING \& MANUFACTURING OF ADVANCED MATERIALS Processing, Fabrication, Properties, Applications

July 9-13, 2018 Paris, FRANCE 


\section{INTRODUCTION}

- Laser shock processing (LSP) is increasingly applied as an effective technology for the improvement of mechanical properties in different types of metallic components, principally as a means of enhancement of their corrosion and fatigue life behavior. Specially wear resistance, stress corrosion cracking susceptibility and crack propagation rate seem to be material properties specially improved by LSP treatments.

- On the other hand, $\mathrm{Mg}$ and its alloys have gained increasing relevance as natural biomaterials as their mechanical properties are in the same range as those corresponding to natural bone as well as due to their inherent bioabsorbable properties.

- In the present paper, the application of the LSP technology to biocompatible bioabsorbable $\mathrm{Mg}$ alloys suitable for chirurgical implementation is envisaged, the experimental verification of the residual stresses fields induced under different processing conditions and the experimental characterization of the corresponding surface properties being specifically considered. 


Laser Shock Processing as an Advanced Technique for the
Surface and Mechanical Resistance Properties Modification of
Bioabsorbable Magnesium Alloys

\section{OUTLI NE:}

- Introduction / Motivation

- Reminder of Laser Shock Processing Principles

- Experimental LSP Setup at CLUPM

- Sample results on the treatment of Metallic Materials of Biomedical I nterest

- Induced Surface Roughness and Residual Stresses in Mg ingot specimens

- I mprovement of Corrosion Behaviour in Mg ingot specimens

- Modified wettability and microorganisms adhesion tolerance in Mg samples

- Discussion and Outlook 


\section{MOTIVATION}

Due to their excellent biodegradability characteristics, $\mathrm{Mg}$ and $\mathrm{Mg}$-based alloys have become an emerging material in biomedical implants, notably for repair of bone as well as coronary arterial stents. However, the main problem with Mg-based alloys is their rapid corrosion in aggressive environments such as human body fluids

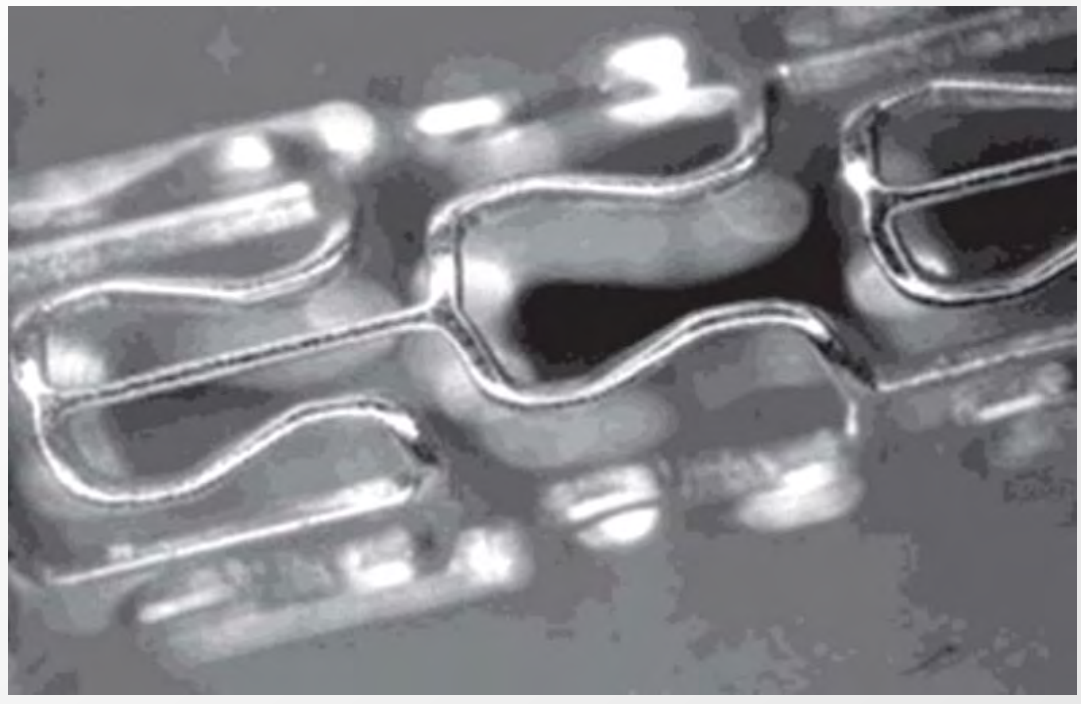

(M. Peuster et al.: doi: 10.1017/S1047951106000011)

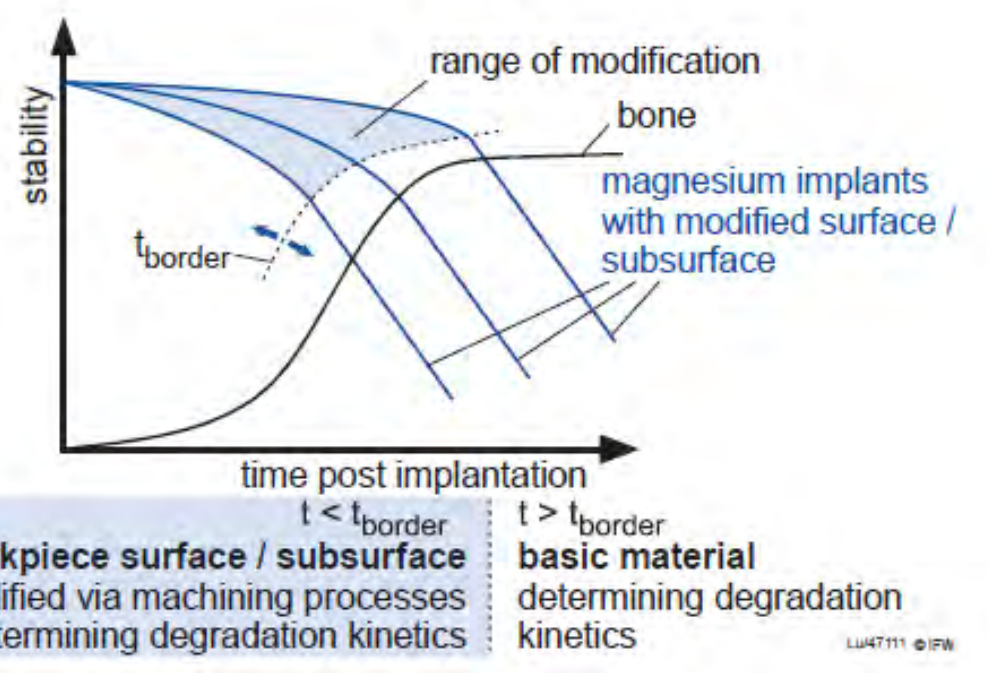

(B. Denkena, A. Lucas.: doi:10.1016/j.cirp.2007.05.029) 


\section{REMINDER OF LSP PHYSICAL PRINCIPLES (1/2)}
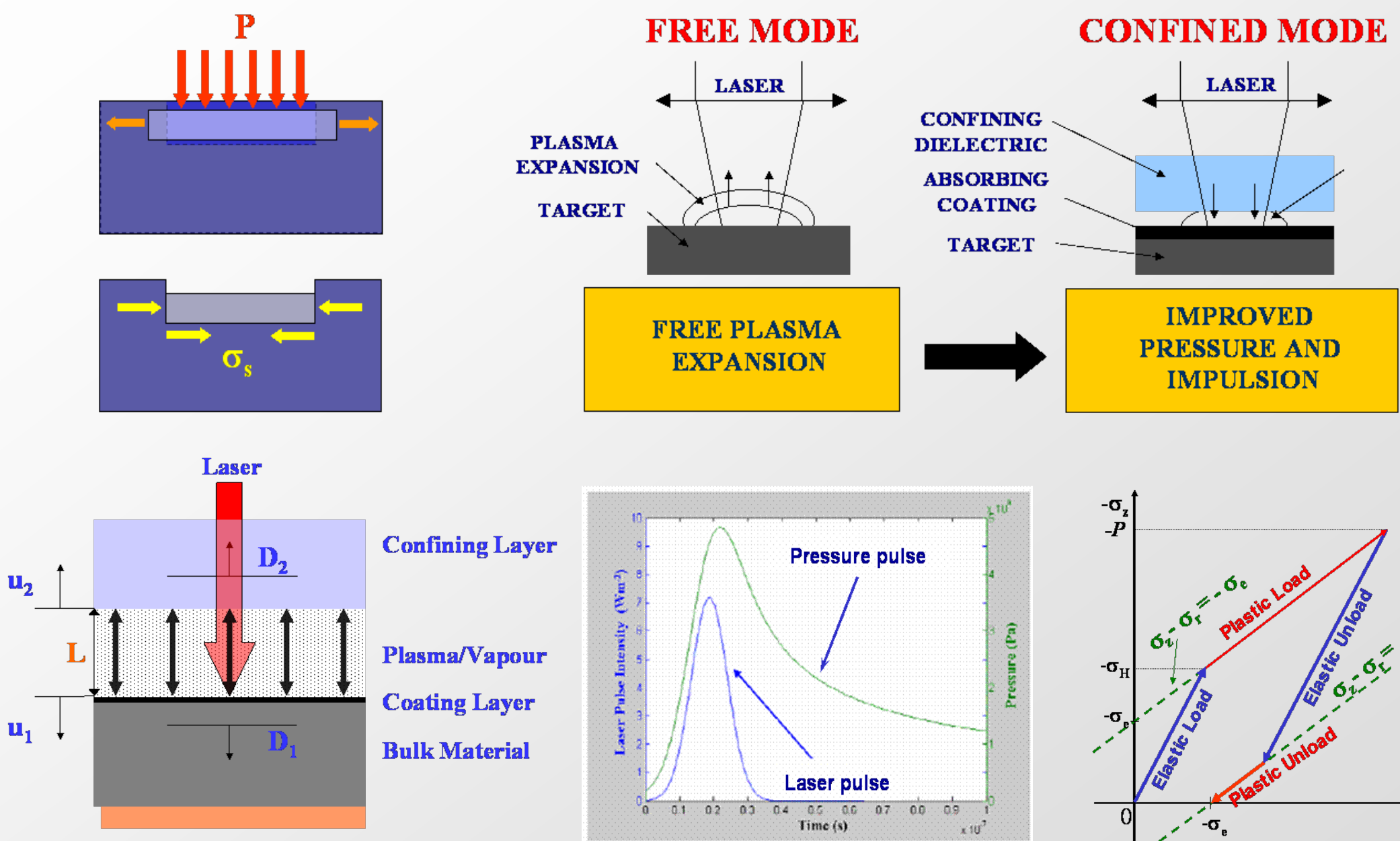

Confining Layer

Plasma/Vapour

Coating Layer

Bulk Material
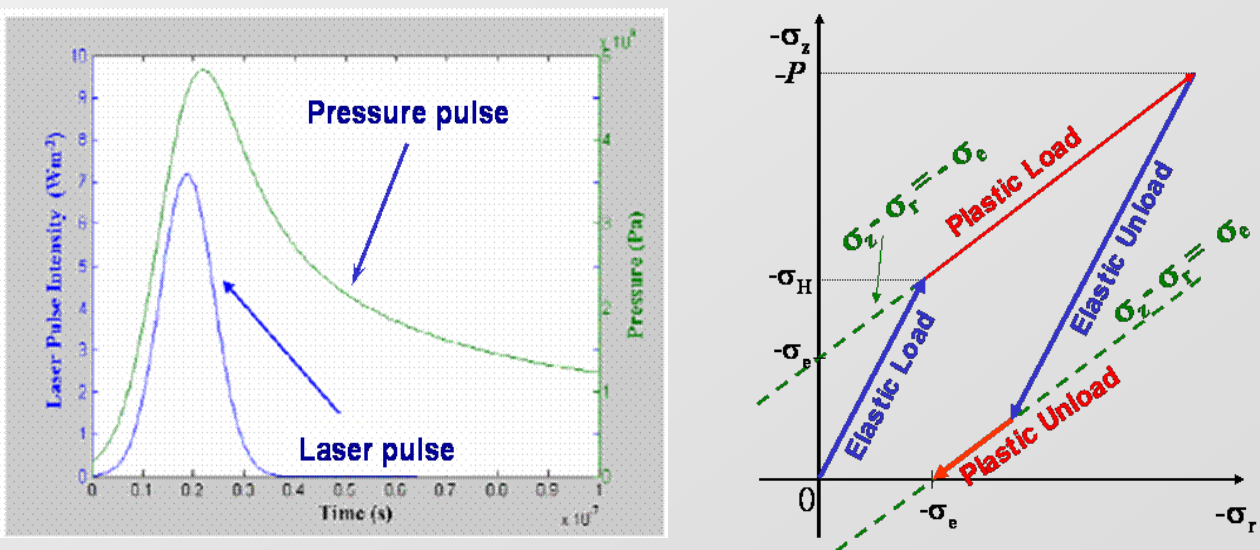


\section{REMINDER OF LSP PHYSICAL PRINCIPLES (2/2)}
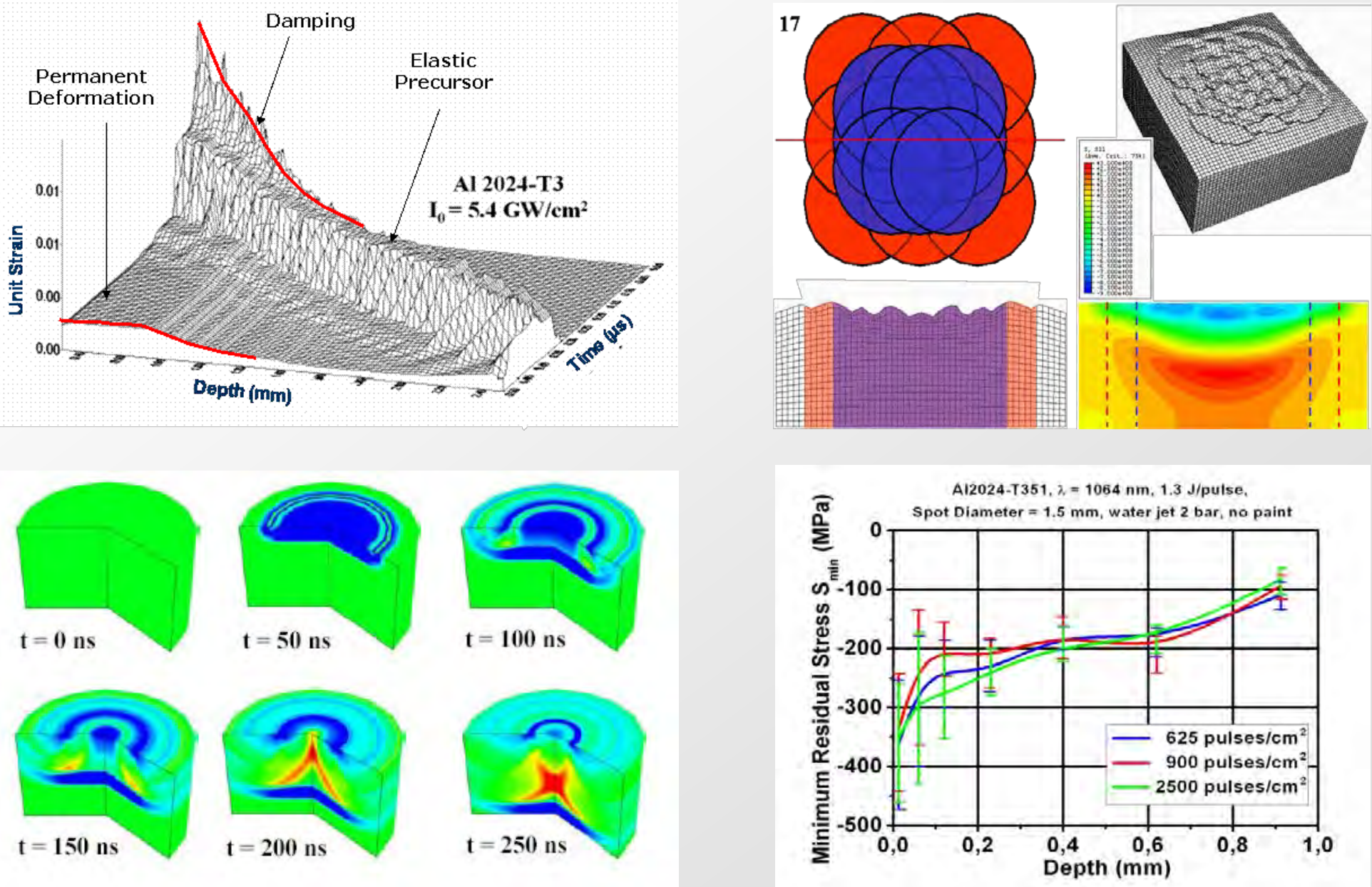

\section{CENTRO LÁSER}

UNIVERSIDAD POLITÉCNICA DE MADRID

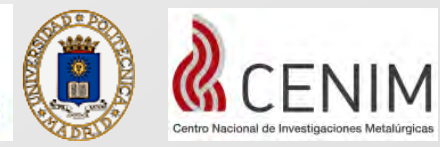

International Conference on

PROCESSING \& MANUFACTURING OF ADVANCED MATERIALS Processing, Fabrication, Properties, Applications 


\section{PROCESS EXPERIMENTAL SETUP}

\section{Q-SWI TCHED Nd:YAG LASER}

$$
\tau=10 \mathrm{~ns} ; \mathrm{f}=10 \mathrm{~Hz}
$$
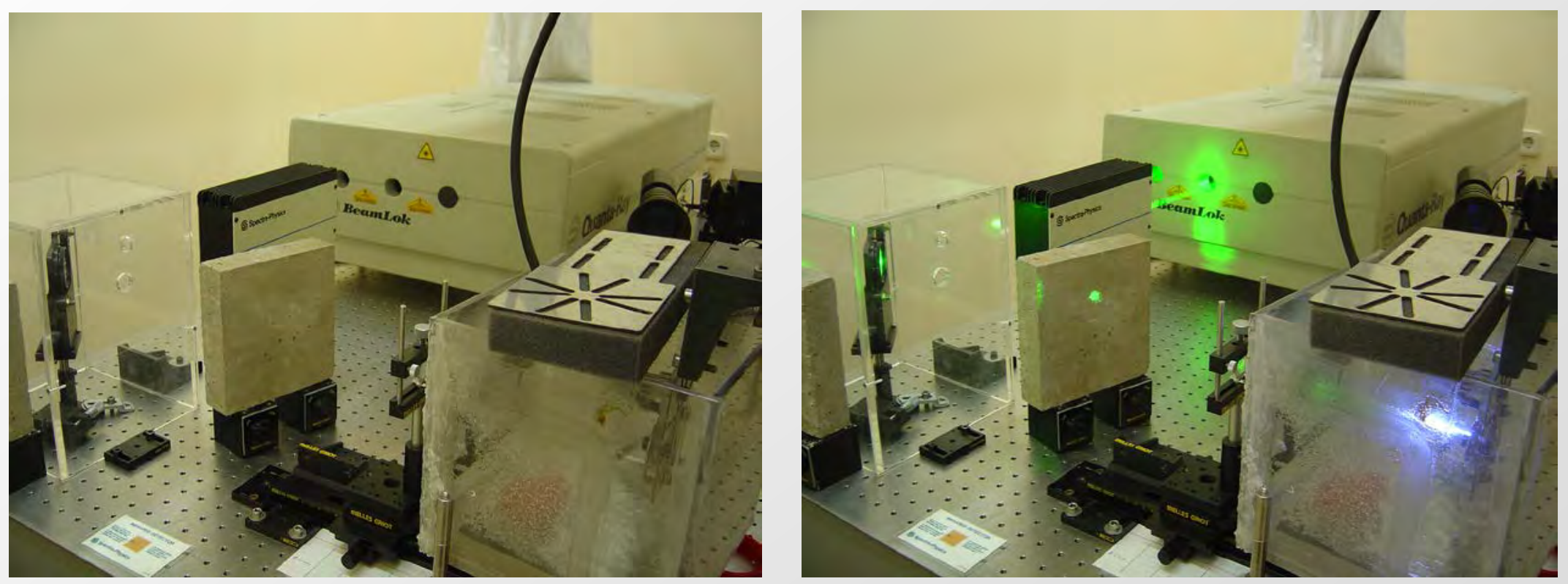

CENTRO LÁSER

UNIVERSIDAD POLITÉCNICA DE MADRID

\section{(a) (IICENIM}

International Conference on PROCESSING \& MANUFACTURING OF ADVANCED MATERIALS Processing, Fabrication, Properties, Applications 


\section{PROCESS EXPERIMENTAL SETUP}

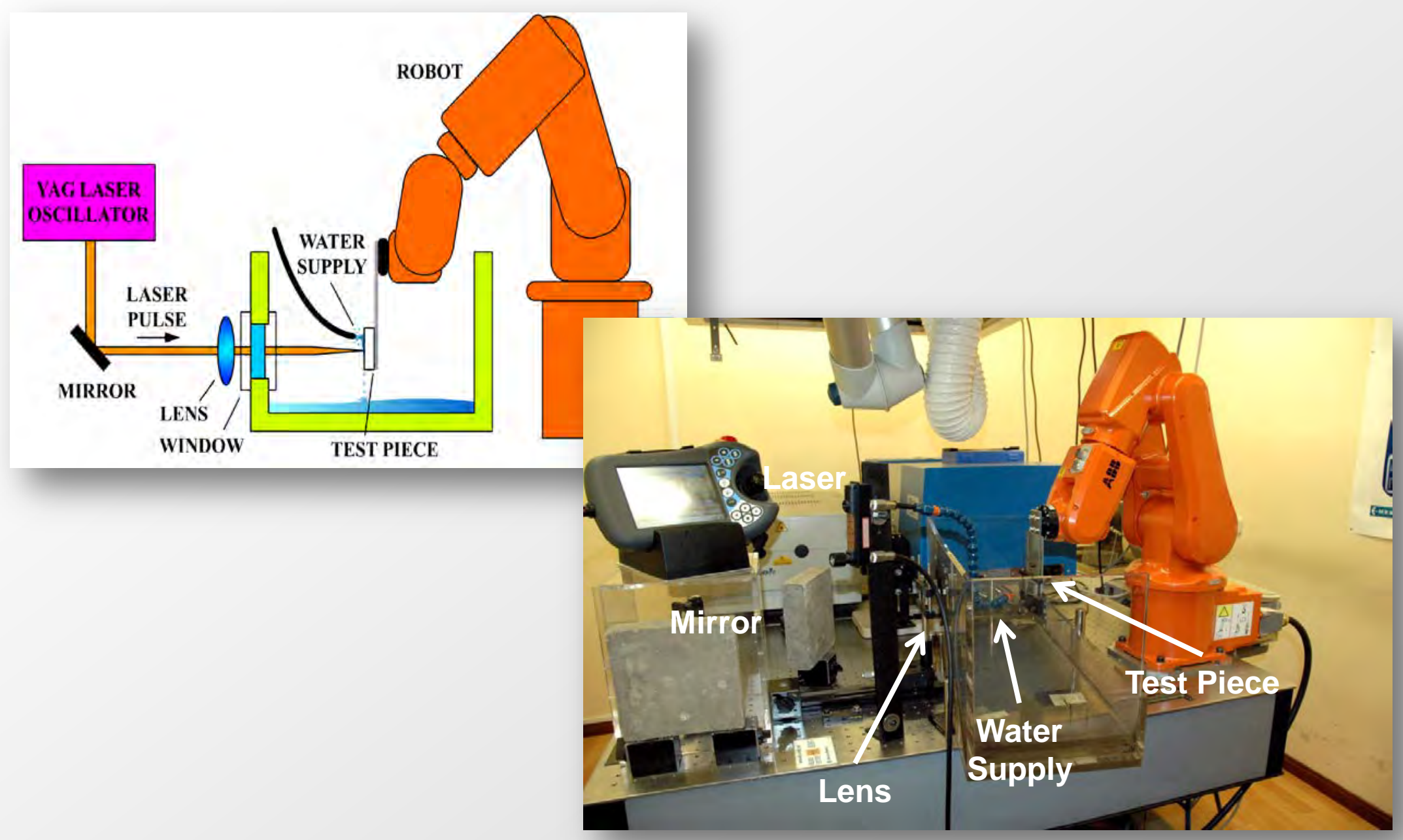

\section{CENTRO LÁSER}

UNIVERSIDAD POLITÉCNICA DE MADRID

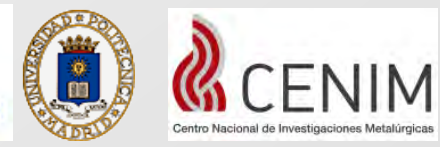

International Conference on PROCESSING \& MANUFACTURING OF ADVANCED MATERIALS Processing, Fabrication, Properties, Applications 


\section{PROCESS EXPERIMENTAL SETUP}

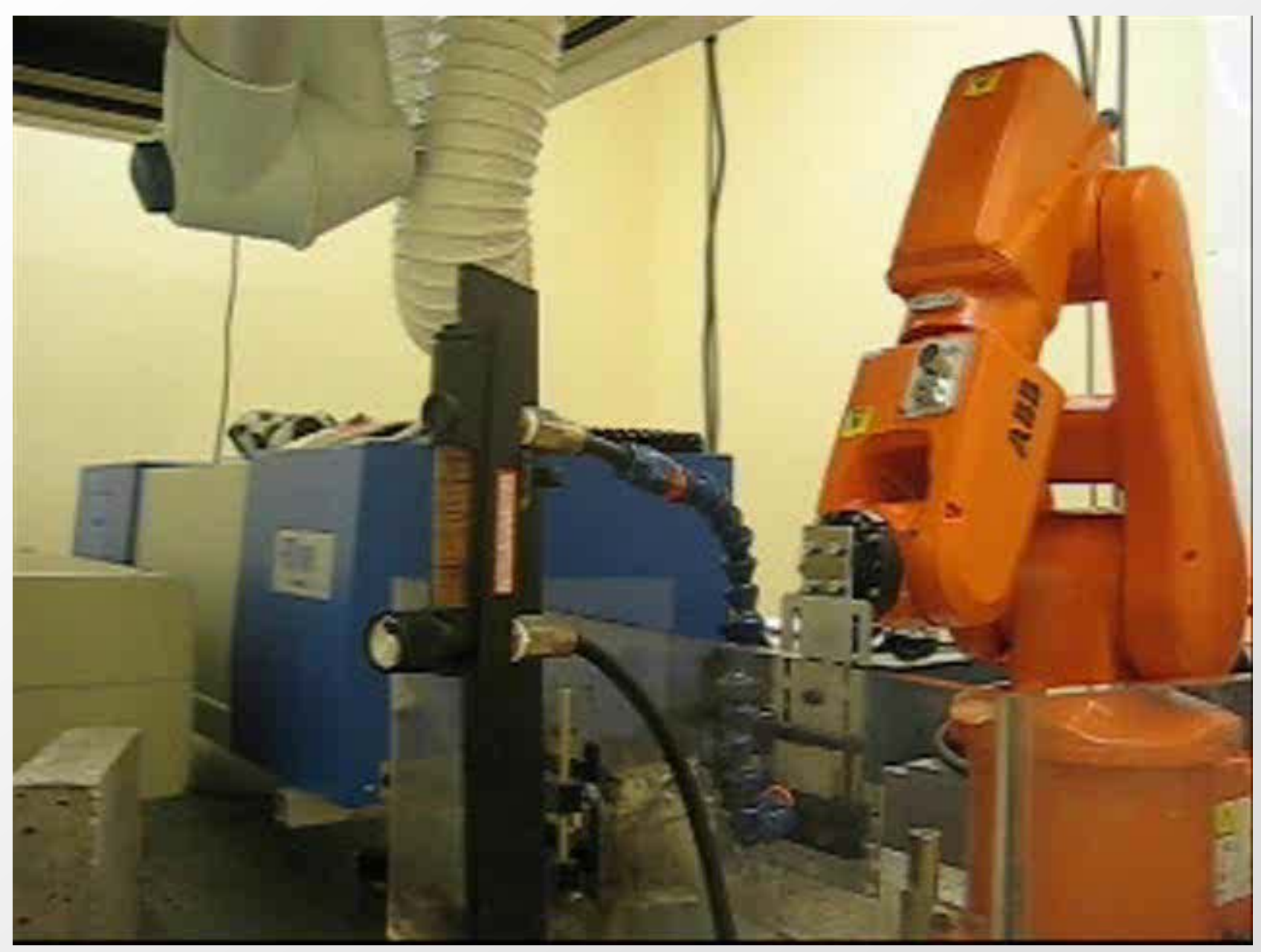

\section{CENTRO LÁSER}

UNIVERSIDAD POLITÉCNICA DE MADRID

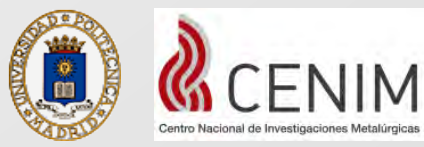

International Conference on PROCESSING \& MANUFACTURING OF ADVANCED MATERIALS Processing, Fabrication, Properties, Applications 


\section{EXPERIMENTAL PROCEDURE}
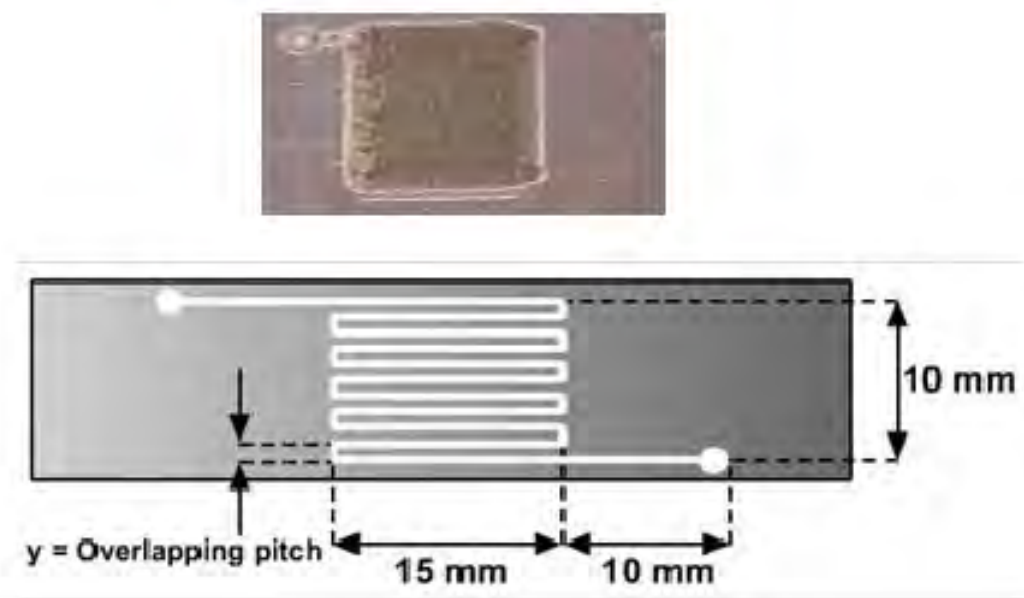

Equivalent
$\begin{aligned} & \text { Overlappin } g \\ & \text { Density }\end{aligned}$

$$
\begin{aligned}
& \begin{array}{l}
\text { Equivalent } \\
\text { Energy }
\end{array} \text { EED }=\frac{N^{o} \text { of pulses } \cdot \text { Pulse Energy }}{\text { Total treated surface }}=\frac{\frac{x}{\Delta x} \frac{y}{\Delta y}}{\Delta s} E=\frac{\frac{x}{d} \frac{y}{d}}{x y} E=\frac{E}{d^{2}} \\
& \begin{array}{l}
\text { Equivalent Local } \\
\text { Overlapping Factor }
\end{array} \equiv \text { ELOF }=\frac{N^{o} \text { of pulses } \cdot \text { Pulse Area }}{\text { Total treated surface }}=\frac{\frac{\pi}{4} \varphi^{2}}{d^{2}}=\frac{\pi}{4}\left(\frac{\varphi}{d}\right)^{2}
\end{aligned}
$$




\section{EXPERIMENTAL RESULTS}

\section{Mg extruded ingot}

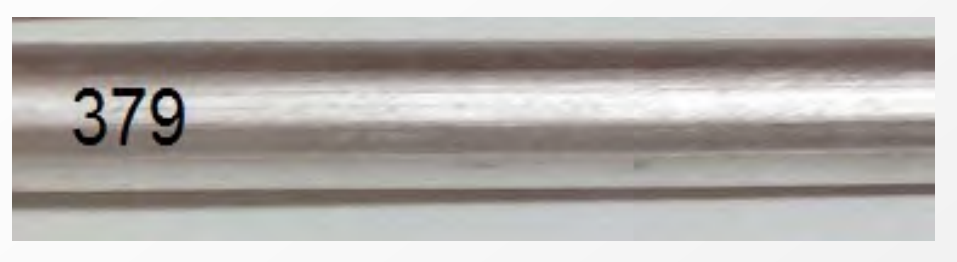

$$
\begin{array}{ll}
\text { YS } & =34-55 \mathrm{MPa} \\
\mathrm{E} & =41-45 \mathrm{GPa}
\end{array}
$$
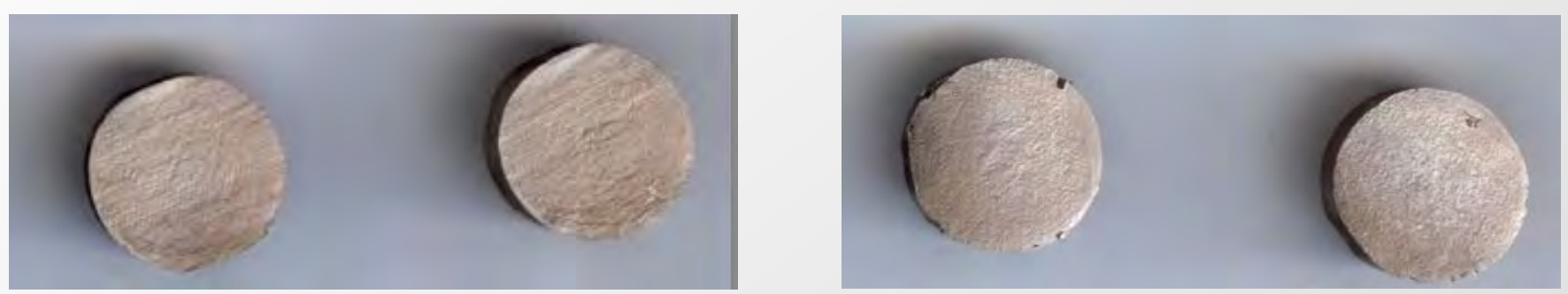

Table 1. LSP processing conditions parameters

\begin{tabular}{|c|c|c|c|c|}
\hline Sample & $\begin{array}{c}\text { Laser Focused } \\
\text { Diameter } \\
\boldsymbol{\varnothing}(\mathbf{m m})\end{array}$ & $\begin{array}{c}\text { LSP treatment } \\
\text { EOD }\left(\mathbf{c m}^{-\mathbf{2}}\right)\end{array}$ & $\begin{array}{c}\text { LSP treatment } \\
\text { EED }\left(\mathbf{J . c m}^{-2}\right)\end{array}$ & $\begin{array}{c}\text { LSP treatment } \\
\text { ELOF (-) }\end{array}$ \\
\hline $1+2$ & 1.5 & 400 & 960 & 7.07 \\
\hline $3+4$ & 2.0 & 400 & 960 & 12.57 \\
\hline
\end{tabular}




\section{EXPERIMENTAL RESULTS}

Table 2. Surface Roughness Parameters Induced in LSP treated samples

\begin{tabular}{|c|c|c|c|c|}
\hline Sample & $\begin{array}{c}\text { Laser Focused } \\
\text { Diameter } \\
\boldsymbol{\varnothing}(\mathbf{m m})\end{array}$ & $\begin{array}{c}\text { LSP treatment } \\
\mathbf{E O D}\left(\mathbf{c m}^{-2}\right)\end{array}$ & $\begin{array}{c}\text { Average Surface } \\
\text { Roughness, } \\
\mathbf{S}_{\mathbf{a}}(\boldsymbol{\mu} \mathbf{m})\end{array}$ & $\begin{array}{c}\text { RMS Surface } \\
\text { Roughness, } \\
\mathbf{S}_{\mathbf{q}}(\boldsymbol{\mu} \mathbf{m})\end{array}$ \\
\hline 0 (Ref) & & & $1.59 \pm 1.0$ & $2.06 \pm 1.0$ \\
\hline 1 & 1.5 & 400 & $12.02 \pm 1.0$ & $15.04 \pm 1.0$ \\
\hline 3 & 2.0 & 400 & $11.46 \pm 1.0$ & $14.43 \pm 1.0$ \\
\hline
\end{tabular}
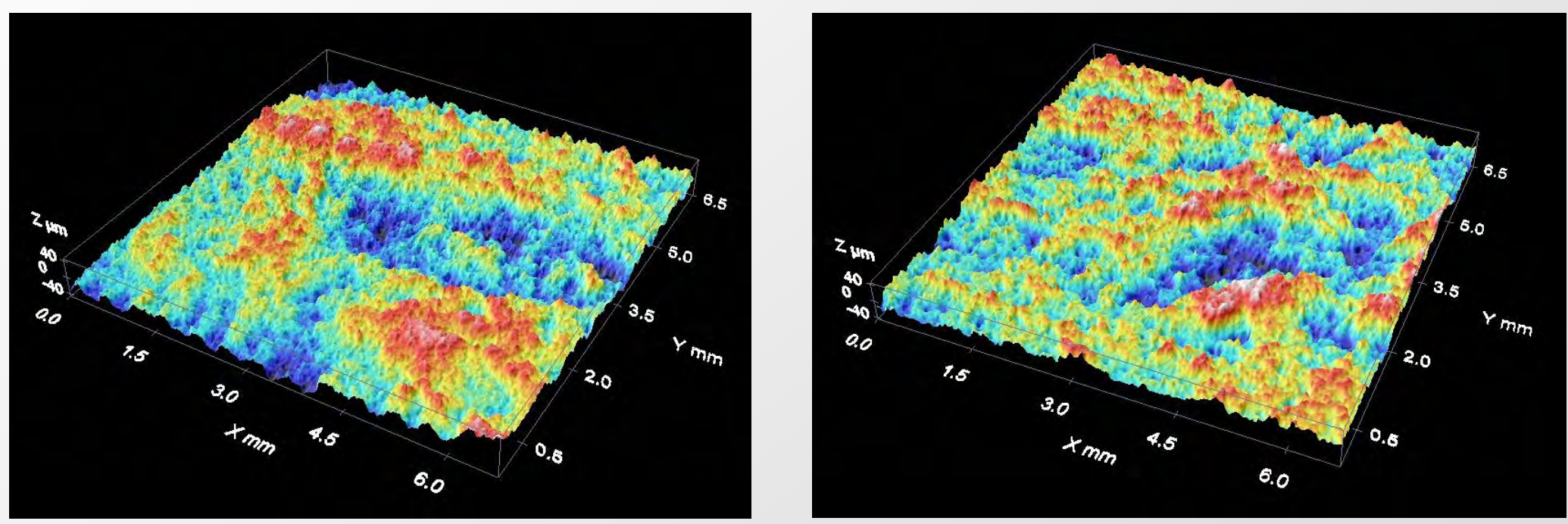

$$
S_{a}=\frac{1}{A} \iint_{A}\left|z(x, y)-z_{a v}\right| d A \quad S_{q}=\sqrt{\frac{1}{A} \iint_{A}\left|z(x, y)-z_{a v}\right|^{2} d A}
$$

According to ISO 25178 Standard

\section{CENTRO LÁSER}

UNIVERSIDAD POLITÉCNICA DE MADRID

\section{(a) (IICENIM}

International Conference on 


\section{EXPERIMENTAL RESULTS}

\section{Residual stresses}

$M$ g Extruded Ingot. $\Phi=1.5 \mathrm{~mm} ; E O D=400 \mathrm{~cm}^{-2}$

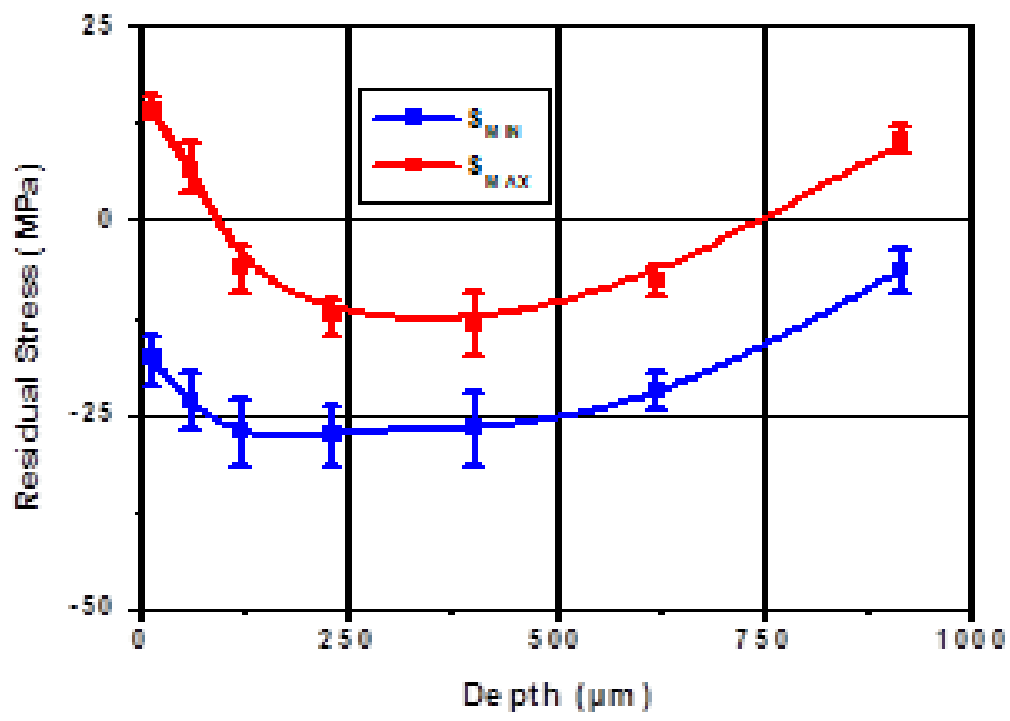

YS $=34-55 \mathrm{MPa}$

$\mathrm{E}=41-45 \mathrm{GPa}$
M g Extruded Ingot. $\Phi=2.0 \mathrm{~mm} ; E O D=400 \mathrm{~cm}^{-2}$

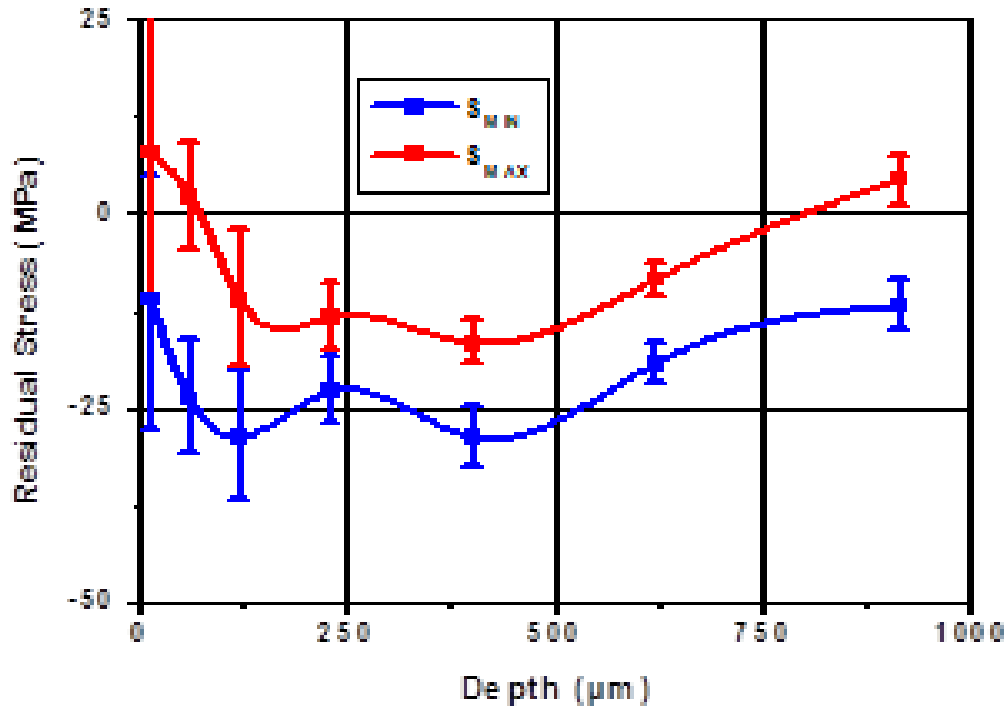

According to ASTM E837-13 Standard 


\section{EXPERIMENTAL RESULTS}

\section{IMPROVED CORROSION BEHAVIOUR (Assessed through EIS):}
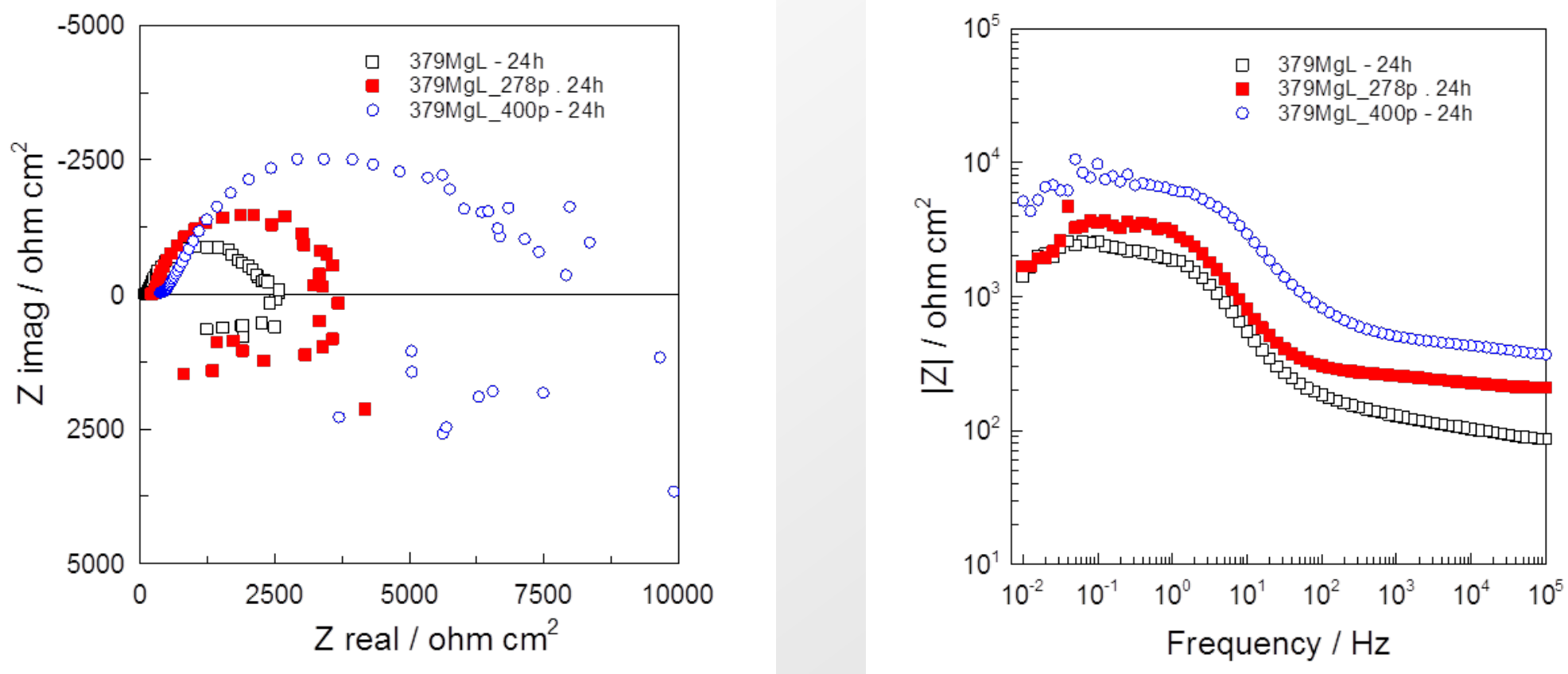

Dulbecco's Phosphate Buffered Saline (Ref. Sigma Aldrich: D8662-500ML) 


\section{EXPERIMENTAL RESULTS}

\section{IMPROVED CORROSION BEHAVIOUR (Assessed through EIS):}
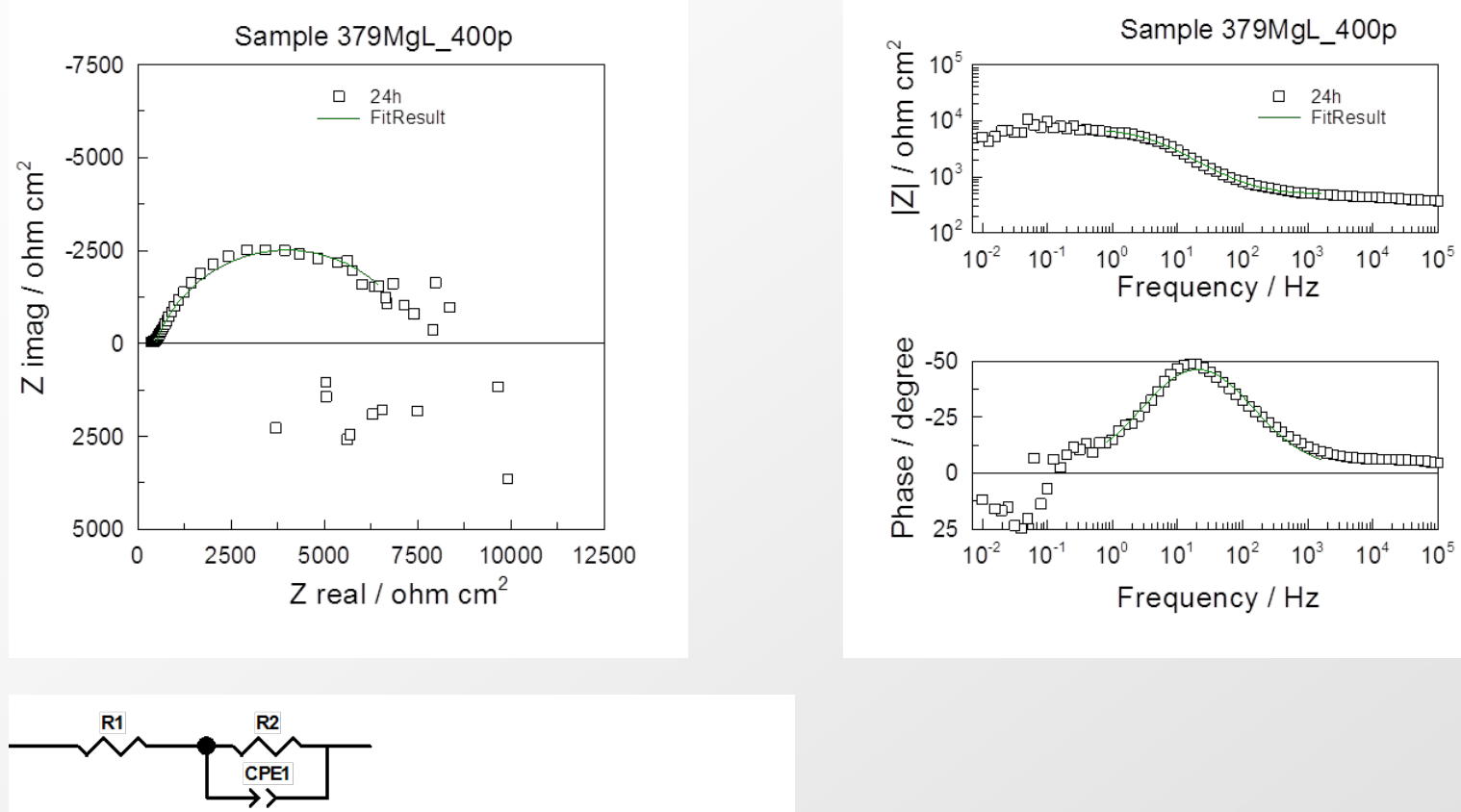

\begin{tabular}{|c|c|c|c|c|}
\hline Element & Freedom & Value & Error & Error \% \\
\hline R1 & Free $( \pm)$ & 479.8 & 6.193 & 1.2907 \\
\hline R2 & Free $( \pm)$ & 7009 & 135.89 & 1.9388 \\
\hline CPE1-T & Free $( \pm)$ & $1.2031 \mathrm{E}-05$ & 4.321E-07 & 3.5916 \\
\hline CPE1-P & Free $( \pm)$ & 0.79244 & 0.0071257 & 0.89921 \\
\hline \multicolumn{2}{|c|}{ Chi-Squared: } & \multicolumn{3}{|l|}{0.0028524} \\
\hline \multicolumn{2}{|c|}{ Weighted Sum of Squares: } & \multicolumn{3}{|l|}{0.18256} \\
\hline
\end{tabular}

$24 \mathrm{~h}$ Test

$\mathrm{R} 1+\mathrm{R} 2=479.8+7009.0=7488.8 \Omega . \mathrm{cm}^{2}$ 


\section{EXPERIMENTAL RESULTS}

\section{IMPROVED CORROSION BEHAVIOUR (Assessed through EIS):}
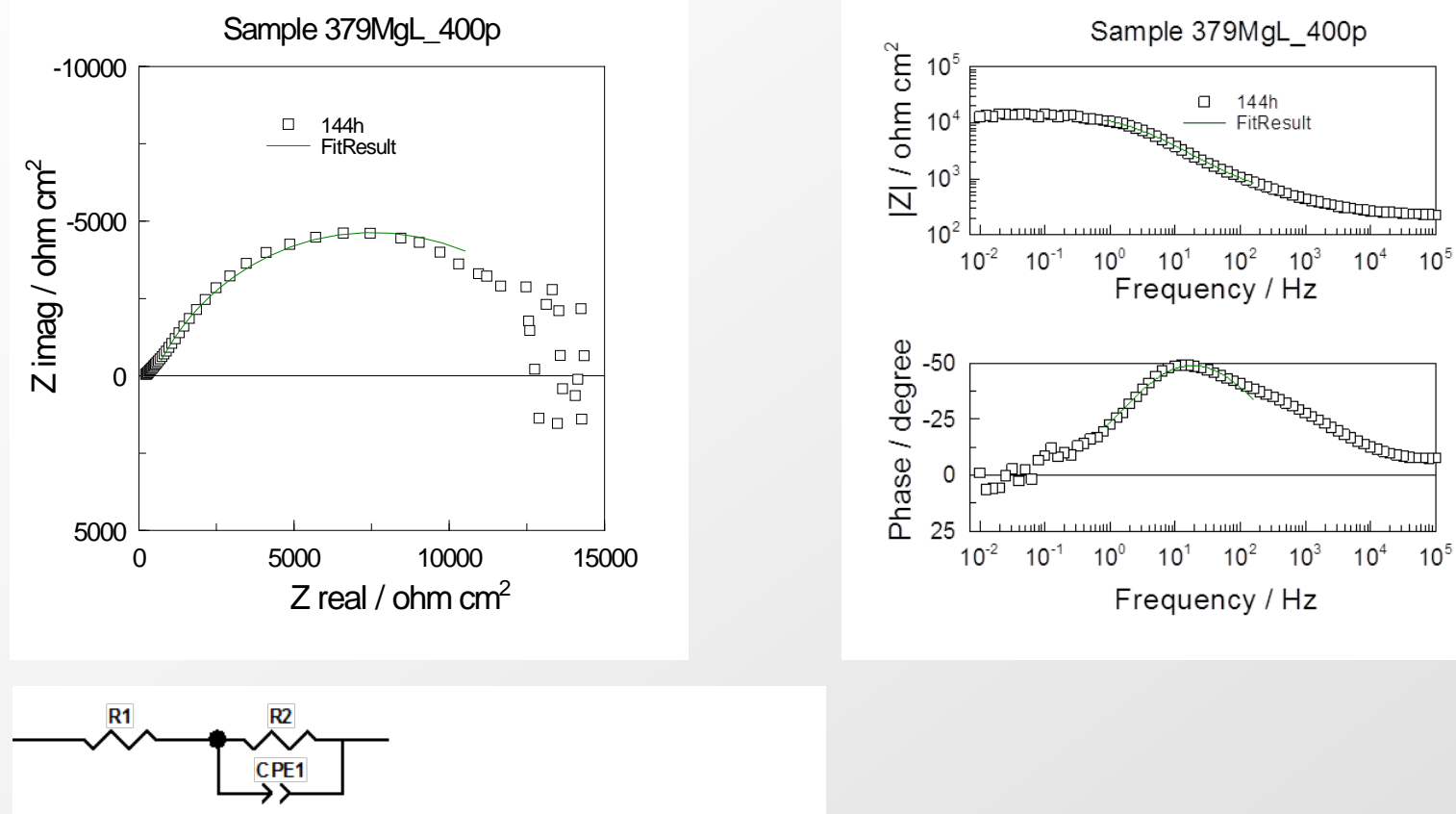

\begin{tabular}{|c|c|c|c|c|}
\hline Element & Freedom & Value & Error & Error \% \\
\hline$\overline{\mathrm{R} 1}$ & Free $( \pm)$ & $\overline{484.3}$ & $\overline{17.923}$ & $\overline{3.7008}$ \\
\hline R2 & Free $( \pm)$ & 14082 & 331.68 & 2.3553 \\
\hline CPE1-T & Free $( \pm)$ & 1.143E-05 & 3.7889E-07 & 3.3149 \\
\hline CPE1-P & Free $( \pm)$ & 0.74094 & 0.0073619 & 0.99359 \\
\hline \multicolumn{2}{|c|}{ Chi-Squared: } & \multicolumn{3}{|l|}{0.0014439} \\
\hline \multicolumn{2}{|c|}{ Weighted Sum of Squares: } & 0.063533 & & \\
\hline
\end{tabular}

\section{$144 \mathrm{~h}$ Test}

$\mathrm{R} 1+\mathrm{R} 2=484.3+14082.0=14567.3 \Omega . \mathrm{cm}^{2}$ 


\section{EXPERIMENTAL RESULTS}
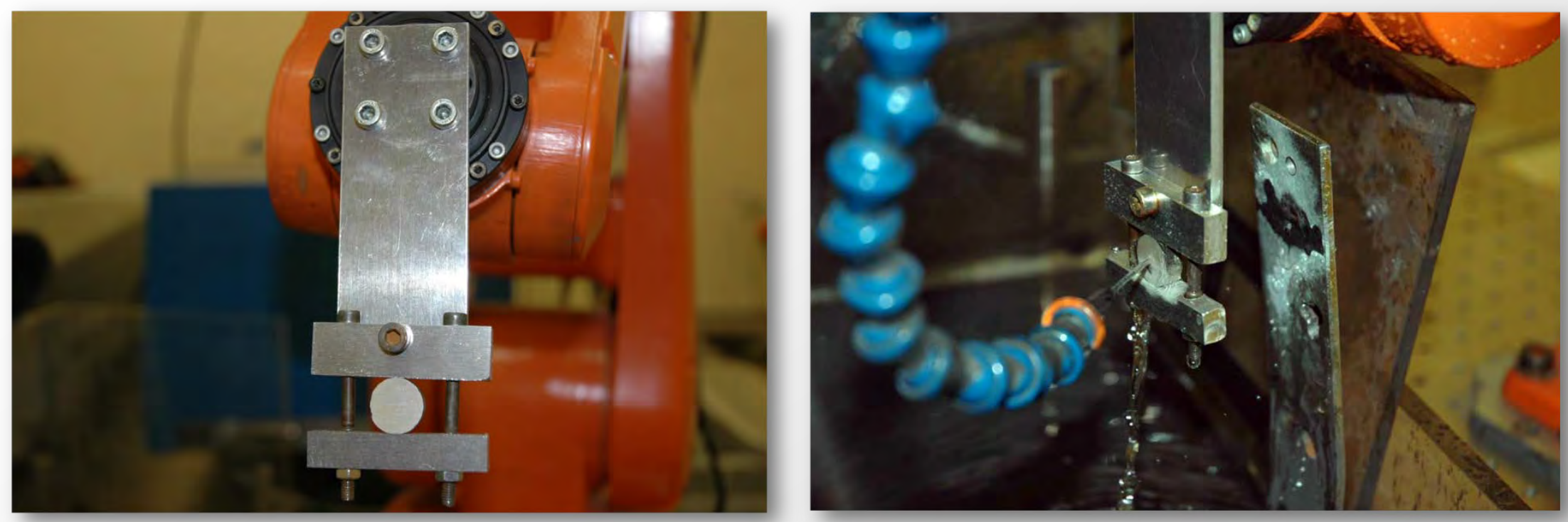

$178 \mathrm{pulsos} / \mathrm{cm}^{2} \quad 223 \mathrm{pulsos} / \mathrm{cm}^{2} \quad 278 \mathrm{pulsos} / \mathrm{cm}^{2} \quad 400 \mathrm{pulsos} / \mathrm{cm}^{2}$

$\varnothing=2.0 \mathrm{~mm}$
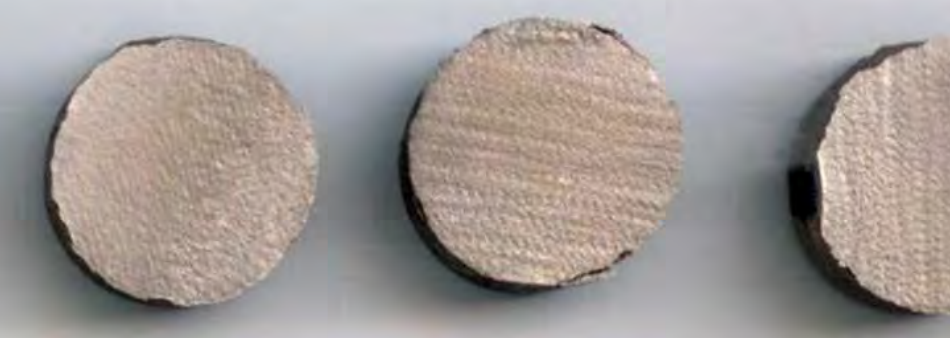

International Conference on 


\section{EXPERIMENTAL RESULTS}

\section{HYDROPHOBICITY:}
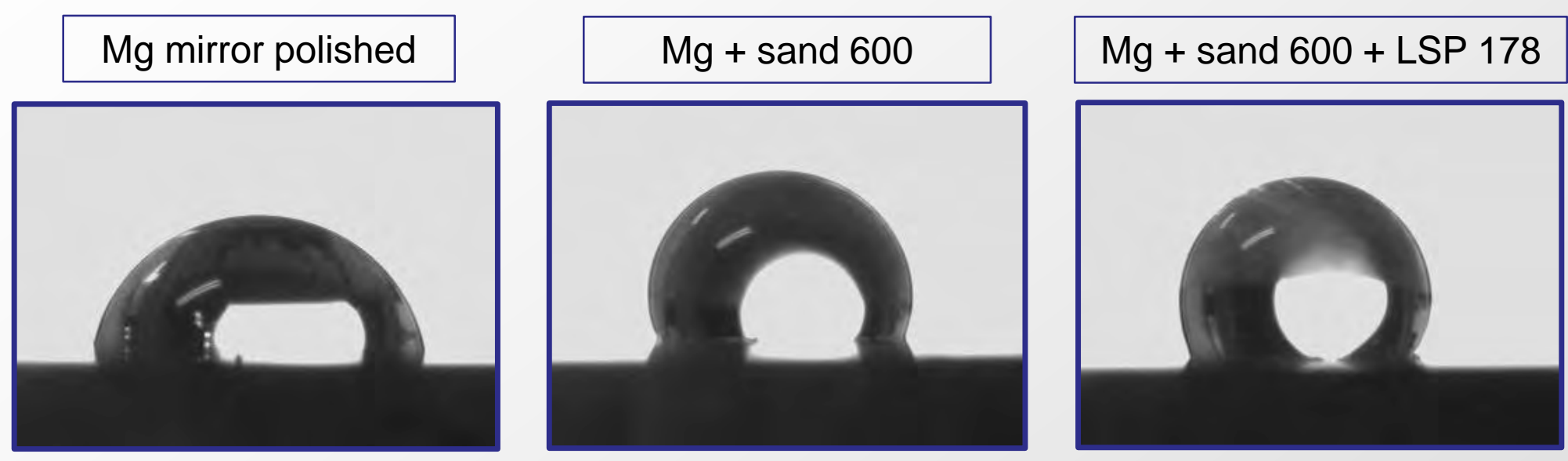

\begin{tabular}{|c|c|}
\hline Sample & Contact Angle (deg) \\
\hline Mg mirror polished & $74 \pm 7$ \\
\hline Mg + sand 600 & $118 \pm 2$ \\
\hline$M g+$ sand 600 + LSP178 & $134 \pm 3$ \\
\hline
\end{tabular}

Data supplied by Research Group on Microbian Adhesion. Univ. of Extremadura (SPAIN) 


\section{EXPERIMENTAL RESULTS}

\section{SURFACE GIBBS ENERGY LOWERING:}
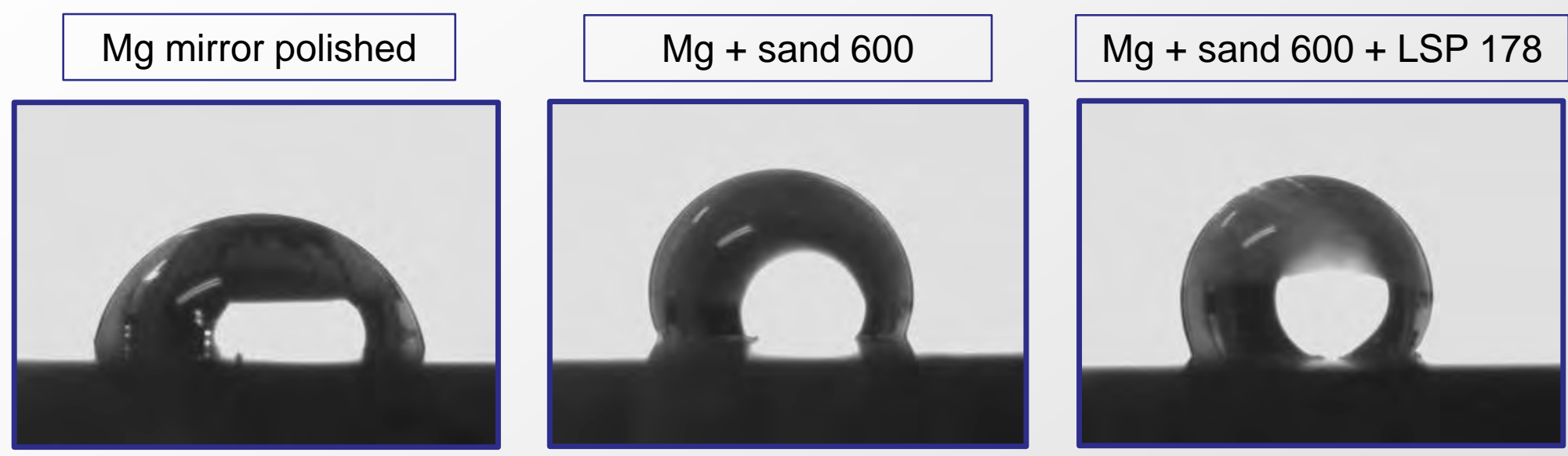

\begin{tabular}{|c|c|}
\hline Sample & S-L Surface Tension $\left(\mathrm{mJ} / \mathrm{m}^{2}\right)$ \\
\hline Mg mirror polished & $43.5 \pm 3.6$ \\
\hline $\mathrm{Mg}+$ sand 600 & $21.2 \pm 5.7$ \\
\hline $\mathrm{Mg}+$ sand $600+\mathrm{LSP} 178$ & $18.8 \pm 2.8$ \\
\hline
\end{tabular}

Data supplied by Research Group on Microbian Adhesion. Univ. of Extremadura (SPAIN) 


\section{EXPERIMENTAL RESULTS}

\section{PROTECTION AGAINST MICROORGANISMS ADHESION:}

Mg mirror polished

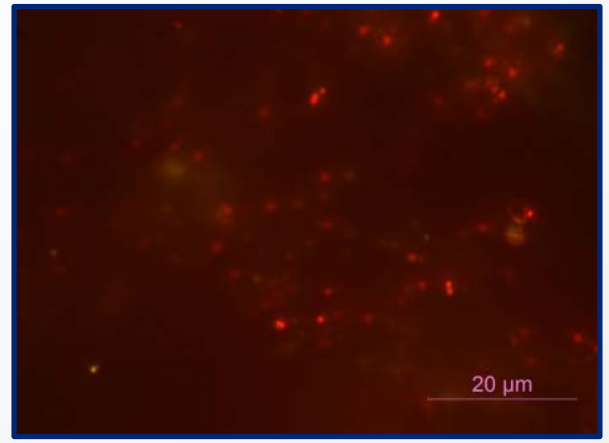

$\mathrm{Mg}+$ sand 600

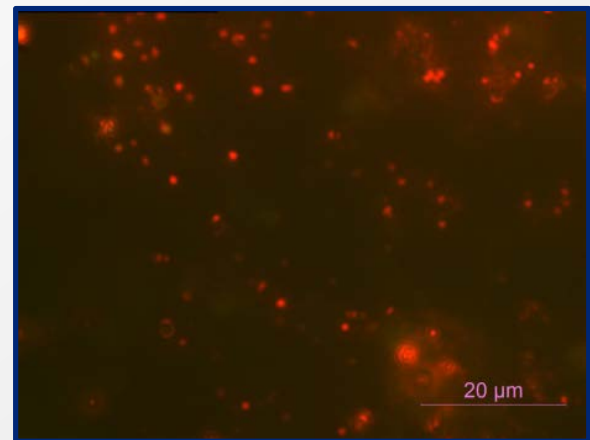

$$
\mathrm{Mg}+\text { sand } 600+\text { LSP } 178
$$

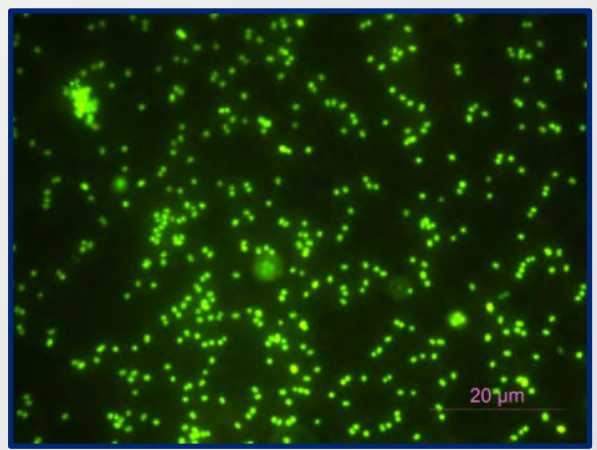

- Microorganism type: Staphylococcus epidermidis ATCC35983.

- Suspension medium: PBS (Phosphate buffered saline).

- Microorganism concentration: 1 McFarland $\left(\approx 3.10^{8} \mathrm{~mL}^{-1}\right)$.

- Adhesion method: Static, $37^{\circ} \mathrm{C}$, slight orbital agitation.

- Contact time: $1 \mathrm{~h}$.

Data supplied by Research Group on Microbian Adhesion. Univ. of Extremadura (SPAIN) 


\section{DISCUSSION AND OUTLOOK}

- According to the presented results, the feasibility of introduction of compressive residual stresses fields in extruded ingot samples of pure Magnesium ( $\mathrm{Mg}>99.9 \%$ ) has been experimentally demonstrated. Maximum compressive residual stresses higher than $45 \%-50 \%$ of the reported yield strength of the material have been achieved by moderate overlapping density $\left(E O D=400 \mathrm{~cm}^{-2}\right)$ treatments with peak laser intensities in the range 8-15 $\mathrm{GW} / \mathrm{cm}^{2}$, providing equivalent energy densities (EED's) in the range $75-150 \mathrm{~J} / \mathrm{cm}^{2}$.

- Taking into account the relatively very low value of the elastic Young modulus and compressive yield stress of such material, the achieved compressive residual stresses values are considered to be well over the minimum values strictly needed for improvement of its surface corrosion resistance.

- Such improvement on corrosion resistance behavior induced by LSP treatments has been experimentally demonstrated by standard EIS tests. The effect has been shown to be stable and even to increase for long test times.

- Additionally, the application of the reported LSP treatments has been found to introduce a moderate increase in surface roughness. These moderate values of the introduced roughness are not considered to have an appreciable influence on the material susceptibilization to crack initiation and result in modified wettability and free energy properties (behavior needed for further study).

- In summary, the feasibility of inducing compressive residual stresses fields over an appreciable depth in this kind of "soft" material is considered to have been experimentally demonstrated under different operational conditions, thus assuring the expected result of improvement of crack propagation retardation and corrosion properties of the material.

- Considering that the presented work is the starting point for application of the LSP technology to different Mg-based bioabsorbable alloys, this technology is considered to be a key one able to change the technological expectations for the practical working limits in the biomedical implants field. 


\section{ACKNOWLEDGEMENTS}

Work partly supported by MINECO (Spain; Projects MAT2012-37782, MAT 2012-37736-C05-01, MAT 2015-63974-C4) and Comunidad de Madrid (Spain; S2013/MIT-2862).

The CIBER of Bioingeniería, Biomateriales y Nanomedicina is supported by the ISCIII (Spain)

\section{MAIN REFERENCES}

1. Ocaña, J.L. et al.: "Predictive assessment and experimental characterization of the influence of irradiation parameters on surface deformation and residual stresses in laser shock processed metallic alloys". In: HighPower Laser Ablation V, Phipps C.R., Ed.. SPIE Vol. 5548, 642-653 (2004)

2. Ocaña, J.L. et al.: Materials Science Forum, 539-543, 1116-1121 (2007)

3. Morales, M. et al.: Surfaces and Coating Technology, $\underline{202}$, 2257-2262 (2008)

4. Morales, M. et al.: Applied Surface Science, 255, 5181-5185 (2009)

5. Ocaña, J.L. et al.: "Design Issues of Engineered Residual Stress Fields and Associate Surface Properties Modification by LSP in Al and Ti Alloys". Proceedings of the Fifth International WLT-Conference on Lasers in Manufacturing 2009. Munich, June 2009. A. Ostendorf et al. Eds.. pp. 387-392 (2009)

6. Martí-López, L. et al.: Applied Optics, 48, 3671-3680 (2009)

7. Ocaña, J.L. et al.: "Laser Shock Processing of Metallic Materials: Coupling of Laser-Plasma Interaction and Material Behaviour Models for the Assessment of Key Process Issues". In International Symposium on High Power Laser Ablation 2010, C.R. Phipps, Ed. AIP Conference Proceedings, Vol. 1278, pp. 902-913 (2010)

8. Morales, M. et al.: Materials Science Forum, 638-642, 2682-2687 (2010)

9. Morales, M. et al.: International Journal of Structural Integrity, 2, 51-61 (2011)

10. Ocaña, J.L. et al.: Materials Science Forum, 706-709, 2565-2570 (2012)

11. Ocaña, J.L. et al.: Materials Science Forum, 783-786, 2376-2381 (2014)

12. Correa, C. et al.: International Journal of Fatigue, $\underline{70}, 196-204$ (2015)

13. Correa, C. et al.: International Journal of Fatigue, $\underline{79}, 1-9$ (2015)

14. Correa, C. et al.: Materials \& Design, $\underline{79}, 106-114$ (2015)

15. Ocaña, J.L. et al.: Journal of Materials Processing Technology, 223, 8-15 (2015)

16. Moreno-Díaz, C. et al.: Journal of Materials Processing Technology, 232, 9-18 (2016)

17. Ocaña, J.L. et al.: Advances in Materials and Processing Technologies, $\underline{3}, 12-22$ (2017)

18. Ocaña, J.L. et al.: Materials Science Forum, $\underline{\mathbf{8 7 9}}$, 1408-1413 (2017) 


\section{The LSP Team at UPM Laser Centre}

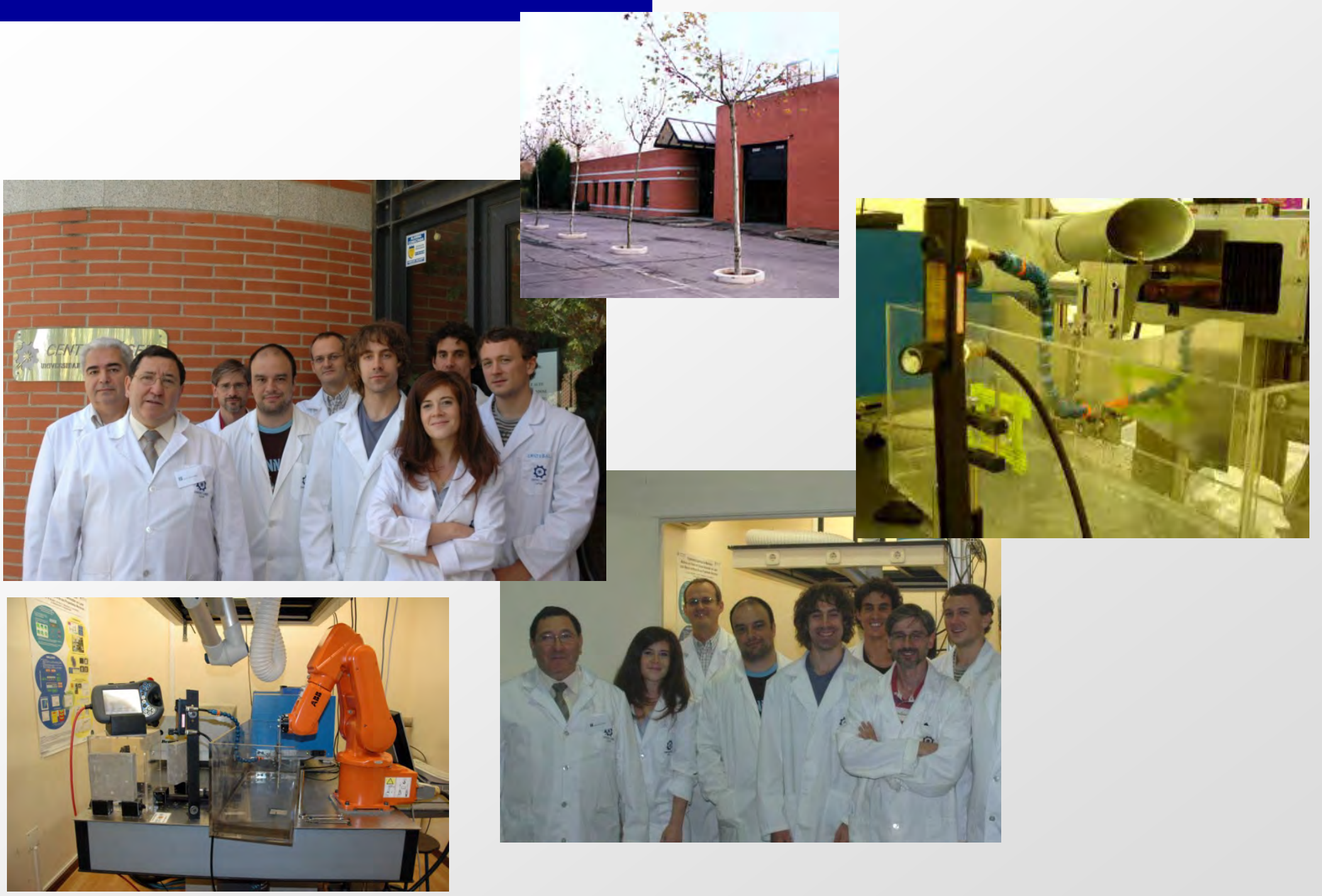

\section{CENTRO LÁSER}

UNIVERSIDAD POLITÉCNICA DE MADRID

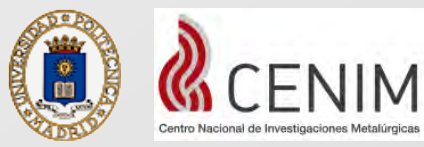

International Conference on PROCESSING \& MANUFACTURING OF ADVANCED MATERIALS Processing, Fabrication, Properties, Applications 

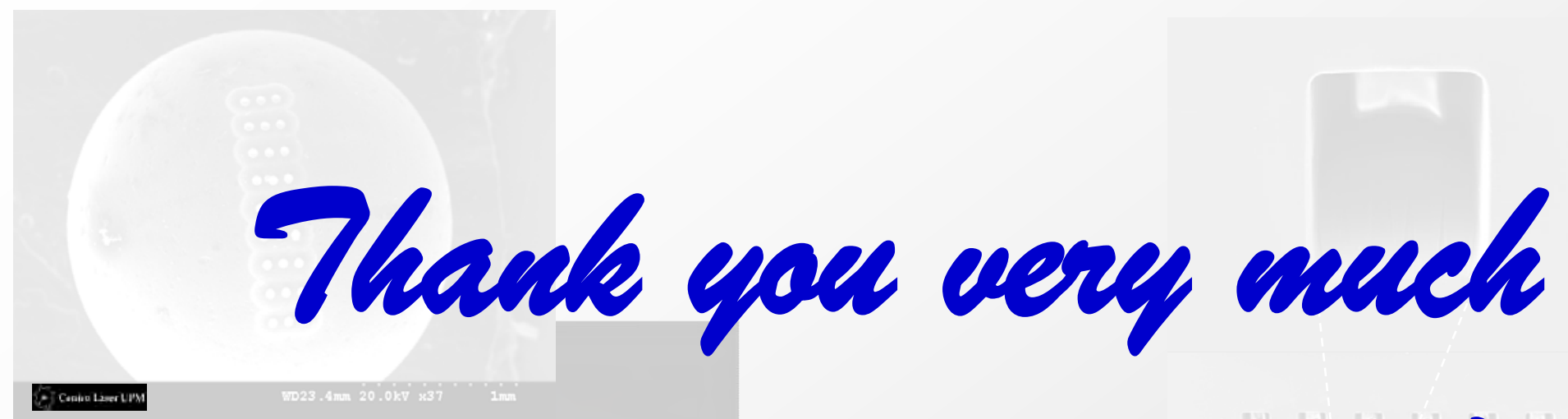

\section{for your attention! \\ $\{$ Centro Láser UPM}

\section{jlocana@etsii.upm.es}




\section{RESULTS: Experimental Procedure for EIS determinations}

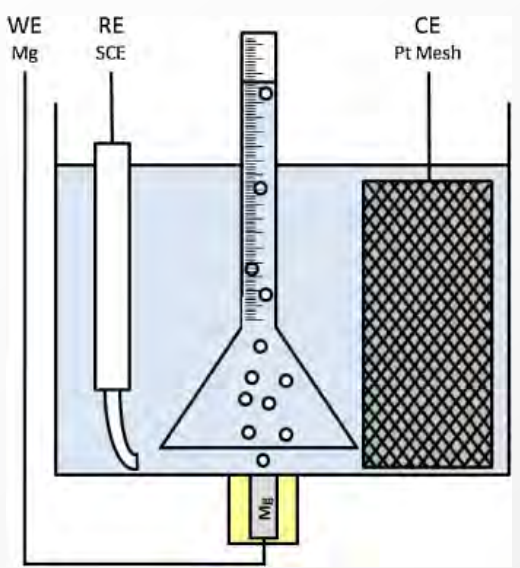

King, A.D., Birbilis, N., Scully, J.R. Electrochimica Acta, 121 (2014), 394-406.

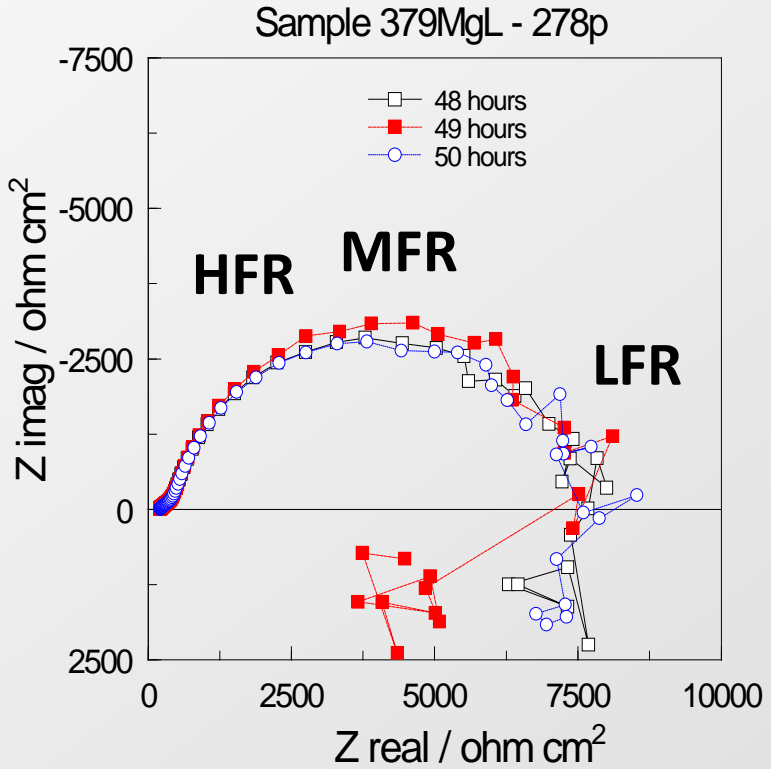

HFR Region associate to behaviour of native oxides or induced by LSP treatments

MFR Region associate to charge transfer resistance (inversely proportional to metal substrate corrosion rate)

LFR Region associate to adsortion/desortion of unstable species 


\section{RESULTS: Experimental Procedure for EIS determinations}

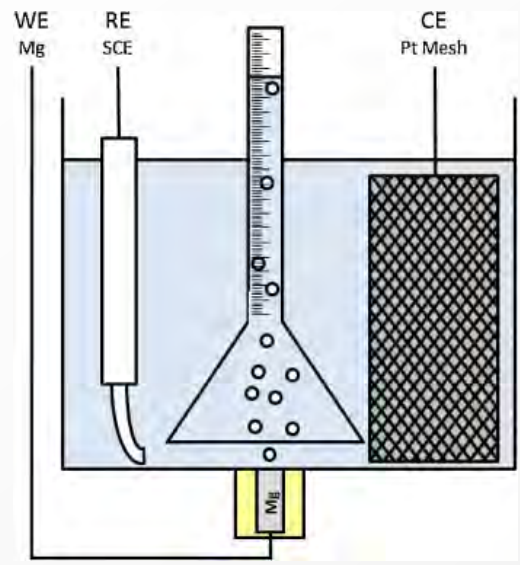

King, A.D., Birbilis, N., Scully, J.R. Electrochimica Acta, 121 (2014), 394-406.

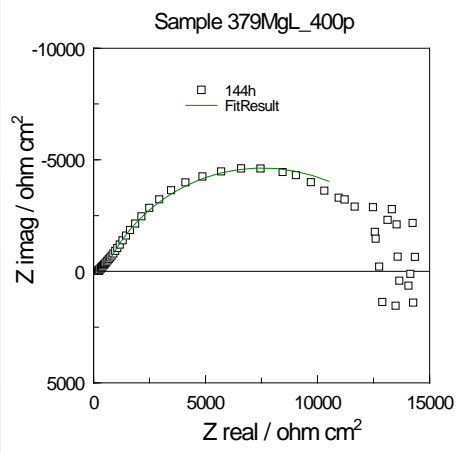

\section{Equivalent circuit}

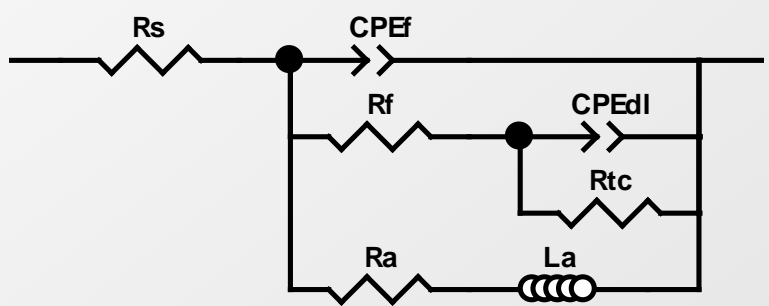

$\mathbf{R}_{\mathrm{s}}$ is the solution resistance.

$R_{f}$ is the resistance of the oxide/hydroxide films (air-formed, LSP, and corrosion products film, respectively).

$\mathbf{R}_{\mathrm{ct}}$ is the charge-transfer resistance of the metal/electrolyte interface (which is inversely proportional to the corrosion rate).

$\mathrm{CPE}_{\mathrm{f}}$ is the capacitance oxide/hydroxide films on magnesium surface (*). $C P E_{d l}$ represents the double-layer capacitance at the interface between magnesium alloy and the solution.

$L_{a}$ and $R_{a}$ represent respectively the inductance and the resistance of adsorbed/desorbed species on the electrode surface.

$\left(^{*}\right)$ In a real system, ideal capacitive behavior is not observed, so a constant phase element (CPE) is often used as a substitute for a capacitor $\mathrm{C}$ to fit more accurately impedance behavior of the electric double layer. 


\section{RESULTS: Experimental Procedure for EIS determinations}

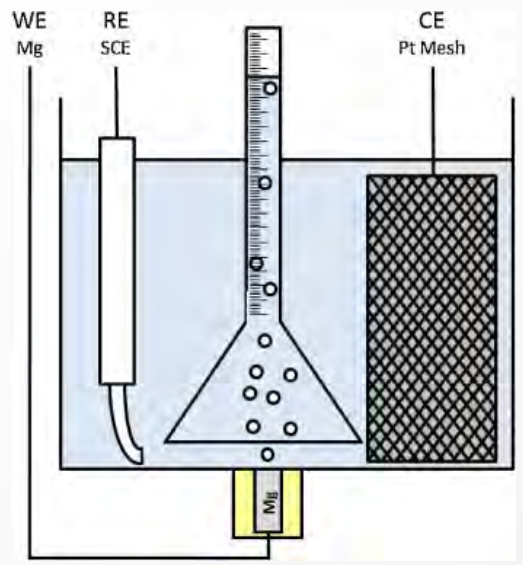

King, A.D., Birbilis, N., Scully, J.R. Electrochimica Acta, 121 (2014), 394-406.

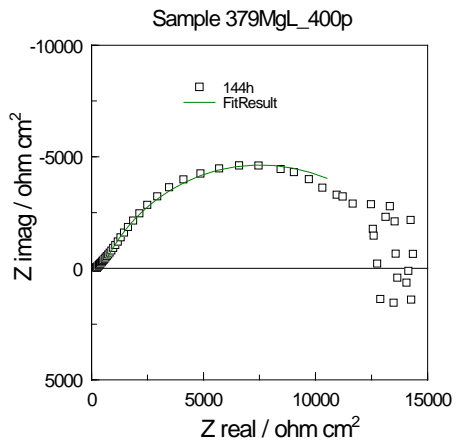

Equivalent circuit

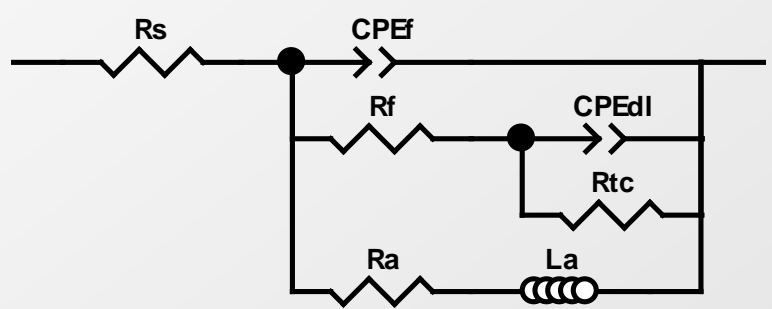

Simplified equivalent circuit (Ignoring the inductive arc of the Nyquist plots)

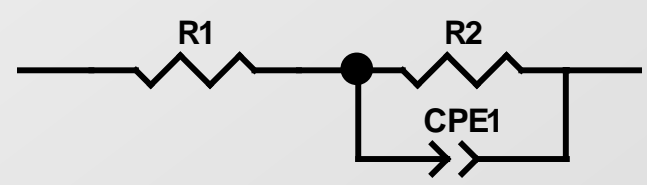

$$
\begin{aligned}
& R_{1}=R_{s}+R_{f} \\
& R_{2}=R_{t} \\
& C P E_{1}=C_{d}
\end{aligned}
$$




\section{RESULTS: Experimental Procedure for EIS determinations}

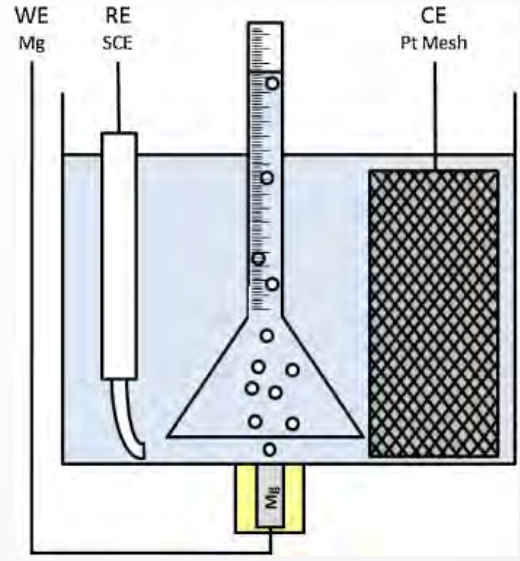

King, A.D., Birbilis, N., Scully, J.R.

Electrochimica Acta, 121 (2014), 394-406.

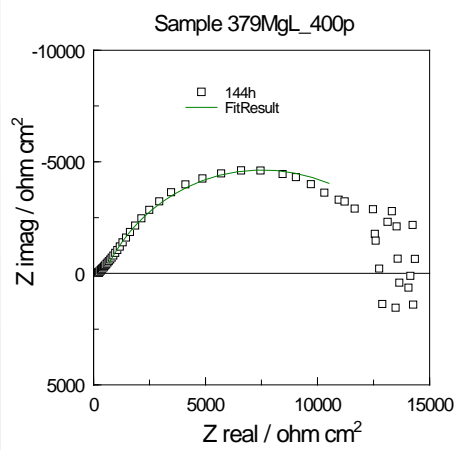

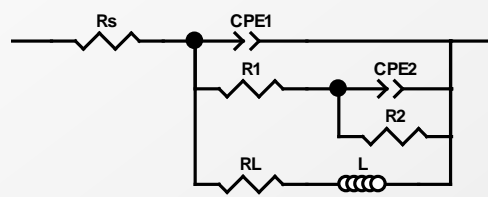

$\mathrm{Rs}+\mathrm{R} 1+\mathrm{R} 2=14578 \Omega . \mathrm{cm}^{-2}$

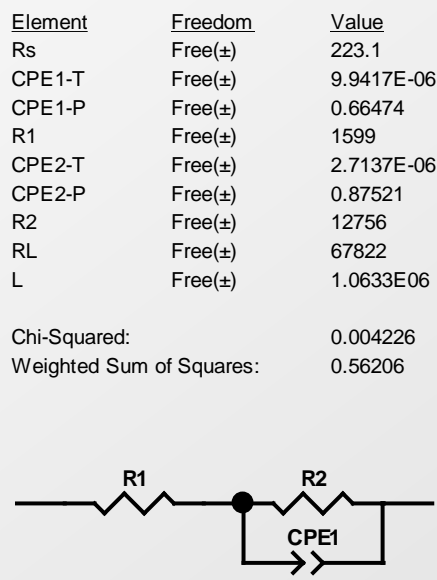

Error

2.4399

$1.4228 \mathrm{E}-06$

0.013318

318.17

$9.0302 \mathrm{E}-07$

0.055603

236.43

13606

$2.0176 \mathrm{E} 05$

1.0936

14.311

2.0035

19.898

33.276

6.3531

1.8535

20.061
18.975

\begin{tabular}{|c|c|c|c|c|}
\hline Element & Freedom & $\underline{\text { Value }}$ & Error & Error \% \\
\hline $\mathrm{R} 1$ & Free $( \pm)$ & 484.3 & 17.923 & 3.7008 \\
\hline R2 & Free $( \pm)$ & 14082 & 331.68 & 2.3553 \\
\hline CPE1-T & Free $( \pm)$ & 1.143E-05 & 3.7889E-07 & 3.3149 \\
\hline CPE1-P & Free $( \pm)$ & 0.74094 & 0.0073619 & 0.99359 \\
\hline \multicolumn{2}{|c|}{ fuared: } & \multicolumn{3}{|l|}{0.0014439} \\
\hline \multicolumn{2}{|c|}{ Weighted Sum of Squares } & 0.063533 & & \\
\hline
\end{tabular}




\section{Open challenges envisaged for real-scale process design and implementation}

- Experimentally validated 2D model-based laser-plasma interaction and plasma dynamics assessment (i.e. locally dependent thermo-mechanical wave applied to treated material).

- In depth evaluation of confining layer breakdown thresholds, with detailed consideration of the effect of different types of protective coatings (specially in high EOD treatments). Possible application of highly adaptable solid media.

- Development of appropriate (experimentally tested) high rate (LSP typical) dynamic material behaviour models.

- In depth parametric analysis of processing windows and scaling laws for different approaches (i.e. high to minimum EOD, EED).

- Further experimental investigation of material transformations (i.e. microstructure, surface and mechanical properties,.. ) under LSP.

- In depth evaluation of thermal / mechanical stability of LSP induced material properties transformations.

- Further exploitation of the capability of LSP predictive assessment tools for the design of concrete purpose oriented applications (i.e. through-thickness compressive RSs fields for crack propagation arresting, surface defects remediation, preventive LSP treatment for extended life,.....). 


\section{EXPERIMENTAL RESULTS}

Material: $\quad$ Al2024 T3

Pulses:

$\varnothing=1,5 \mathrm{~mm} ; \tau=10 \mathrm{~ns} ; \mathrm{f}=10 \mathrm{~Hz}$;

$E=1 \mathrm{~J} /$ pulse; $l=1,41 \mathrm{GW} / \mathrm{cm}^{2}$

Swept Area : $15 \times 15 \mathrm{~mm}^{2} ; 2500$ pulses $/ \mathrm{cm}^{2}$
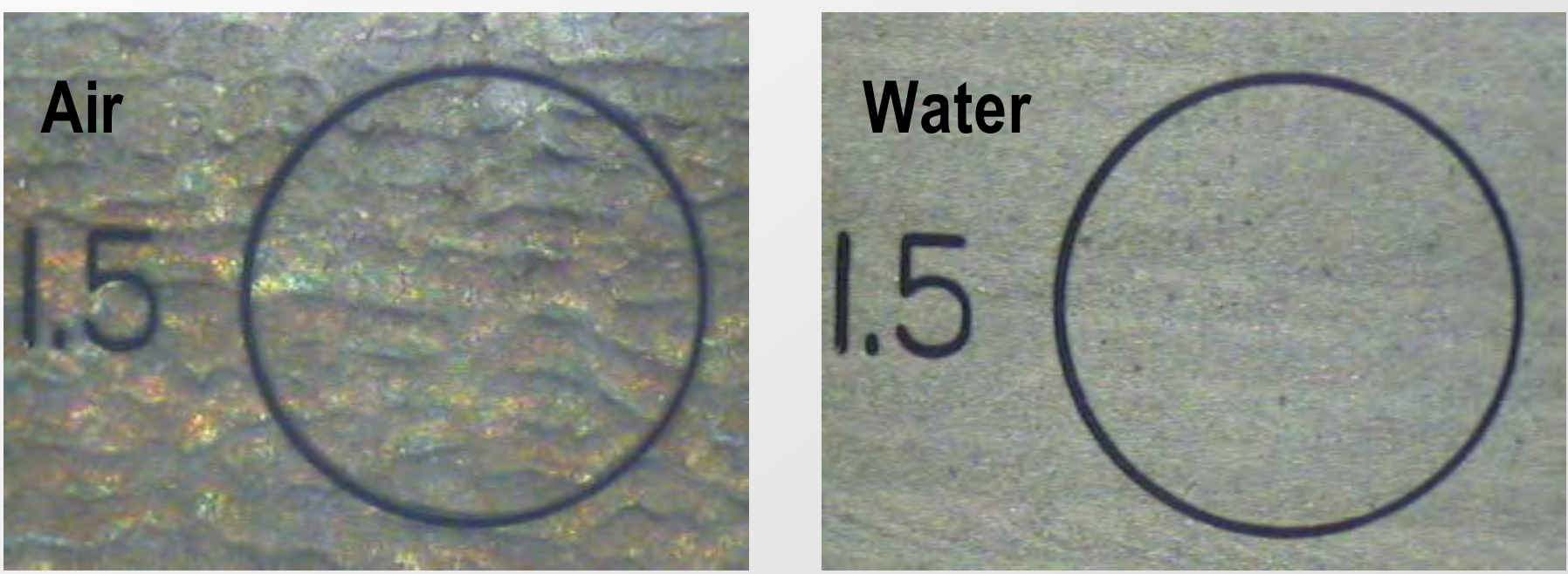


\section{SHOCK PROPAGATION AND DERIVED RESIDUAL STRESSES IN LSP}

Evaluation of relative effects of thermal and mechanical waves on shocked material

Water I Aluminium; Nd:YAG (1064 nm),

$\tau=9 \mathrm{~ns}, \mathrm{~F}=84 \mathrm{~J} / \mathrm{cm}^{2}$, radius $=1.5 \mathrm{~mm}$
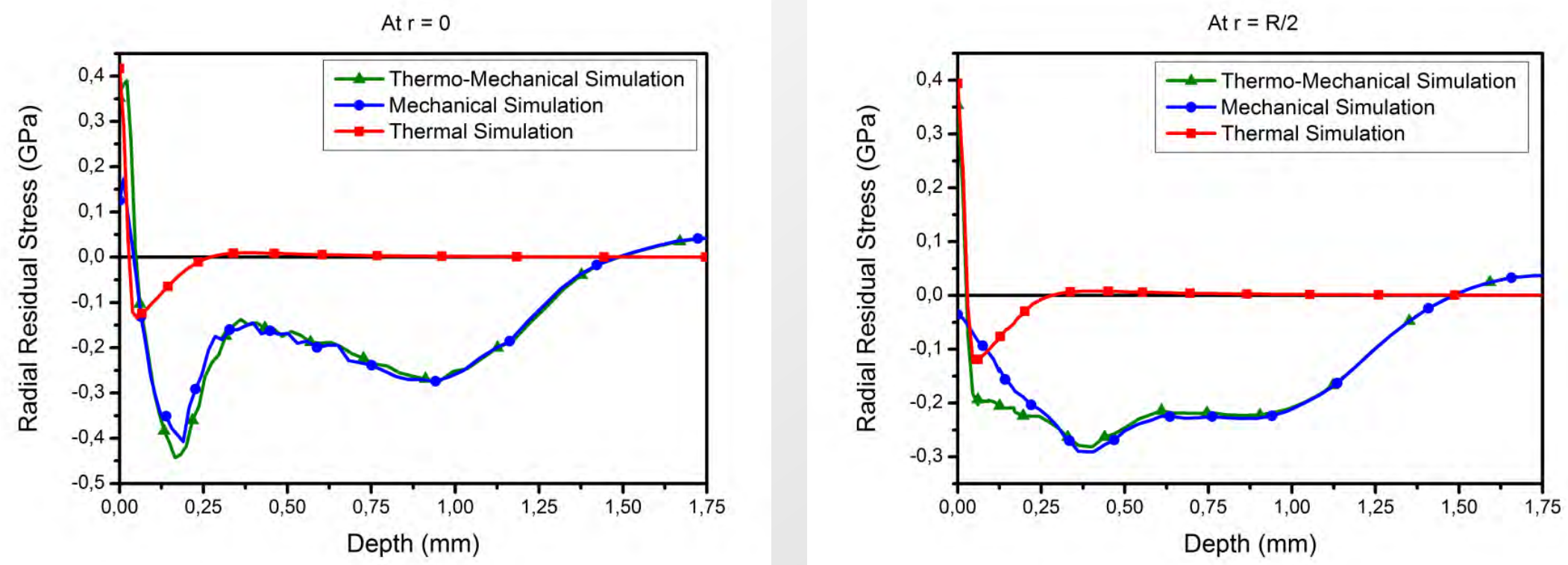

Morales, M. et al.: Materials Science Forum, 638-642, 2682-2687 (2010) 

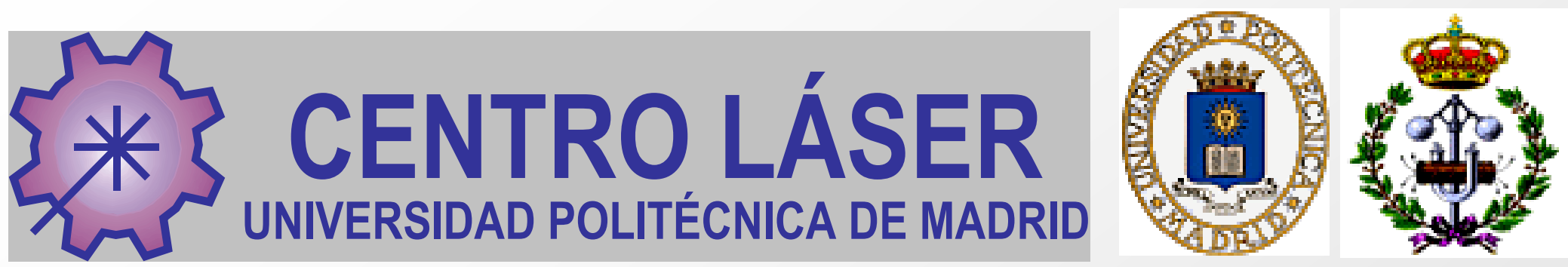

\section{Centro Láser U.P.M.}

Campus Sur U.P.M.

Edificio Tecnológico "La Arboleda"

Carretera de Valencia km. 7,300 28031 Madrid - SPAIN

Tel. : (+34) 913363099

Fax.: (+34) 913365534

Email: claser@etsii.upm.es

ilocana@etsii.upm.es

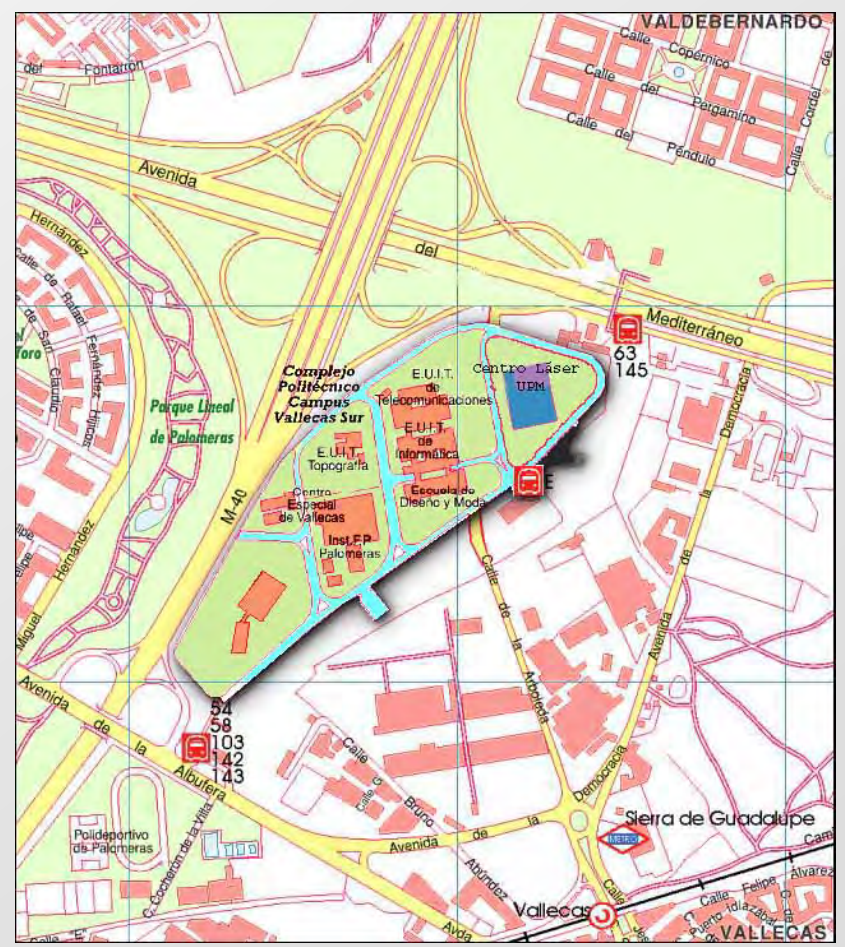




\section{Major Facilities (1/4)}
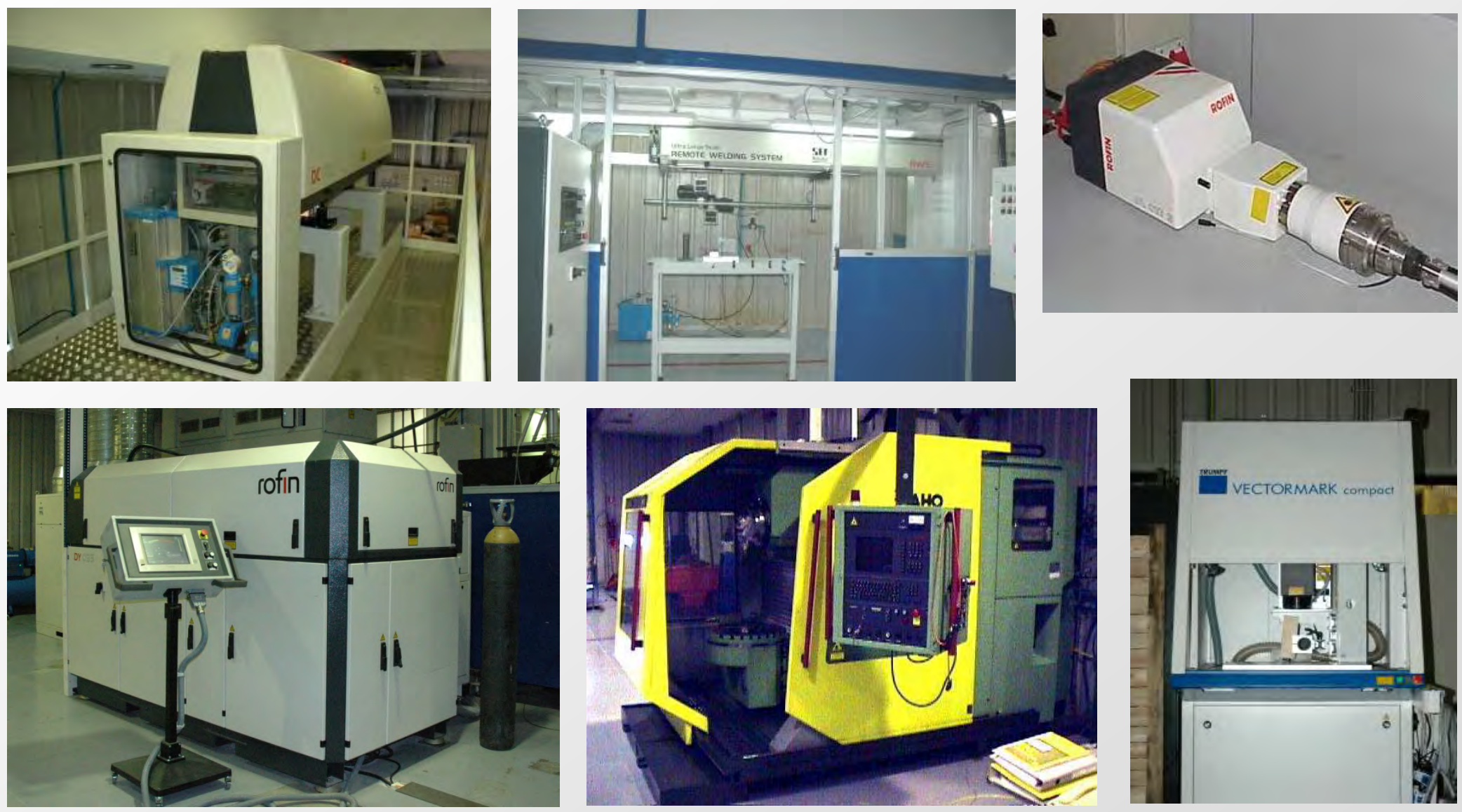

* CENTRO LÁSER UNIVERSIDAD POLITÉCNICA DE MADRID

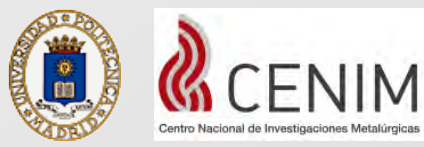

International Conference on PROCESSING \& MANUFACTURING OF ADVANCED MATERIALS Processing, Fabrication, Properties, Applications 


\section{Major Facilities (2/4)}
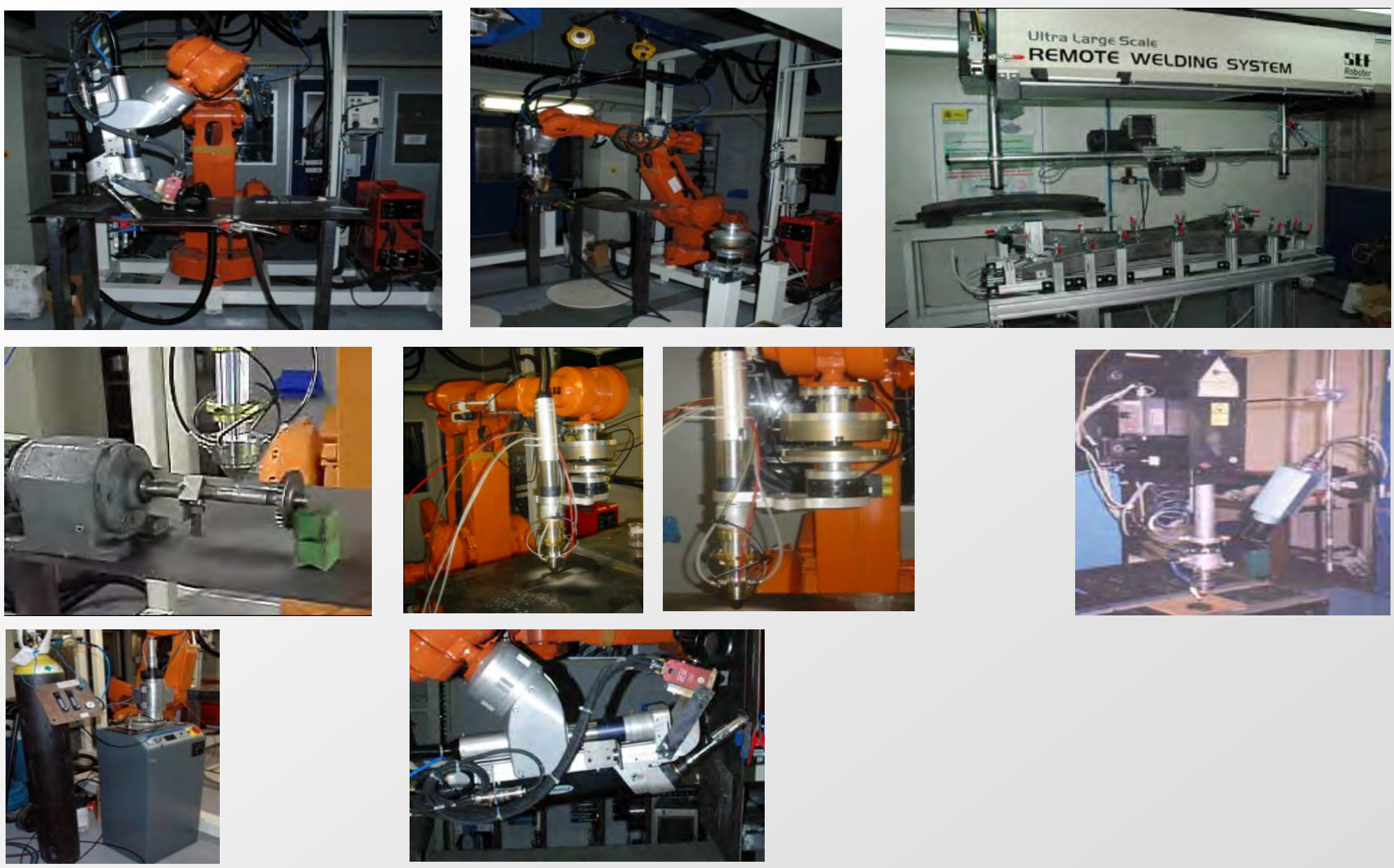

* CENTRO LÁSER

* UNIVERSIDAD POLITECCNICA DE MADRID

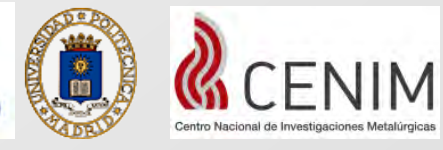

International Conference on PROCESSING \& MANUFACTURING OF ADVANCED MATERIALS Processing, Fabrication, Properties, Applications 


\section{Major Facilities (3/4)}
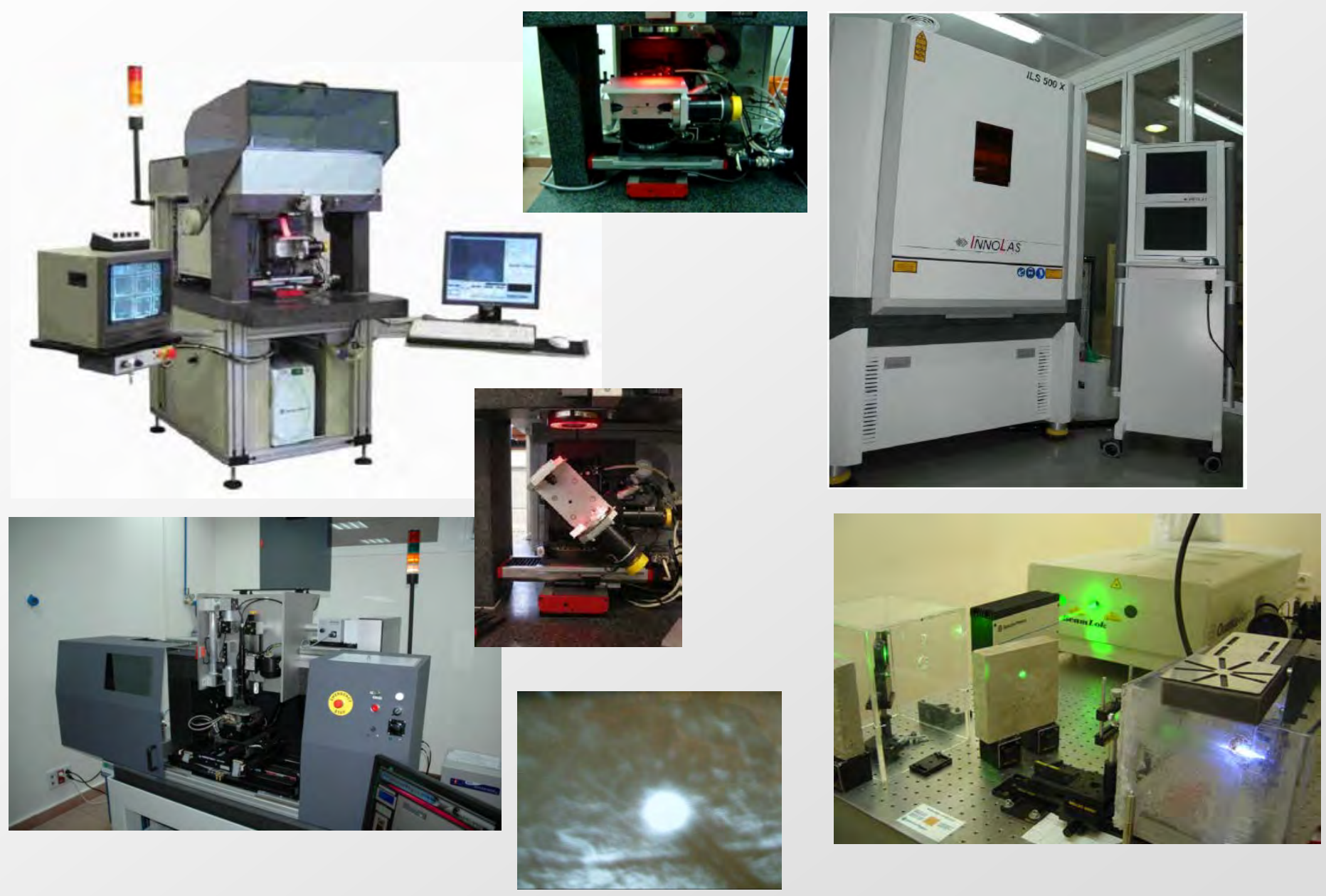

* CENTRO LÁSER UNIVERSIDAD POLITÉCNICA DE MADRID

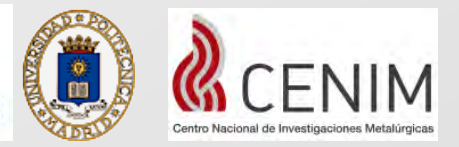

PROCESSING \& International Conference on Processing, Fabrication, Properties, Applications 


\section{Major Facilities (4/4)}
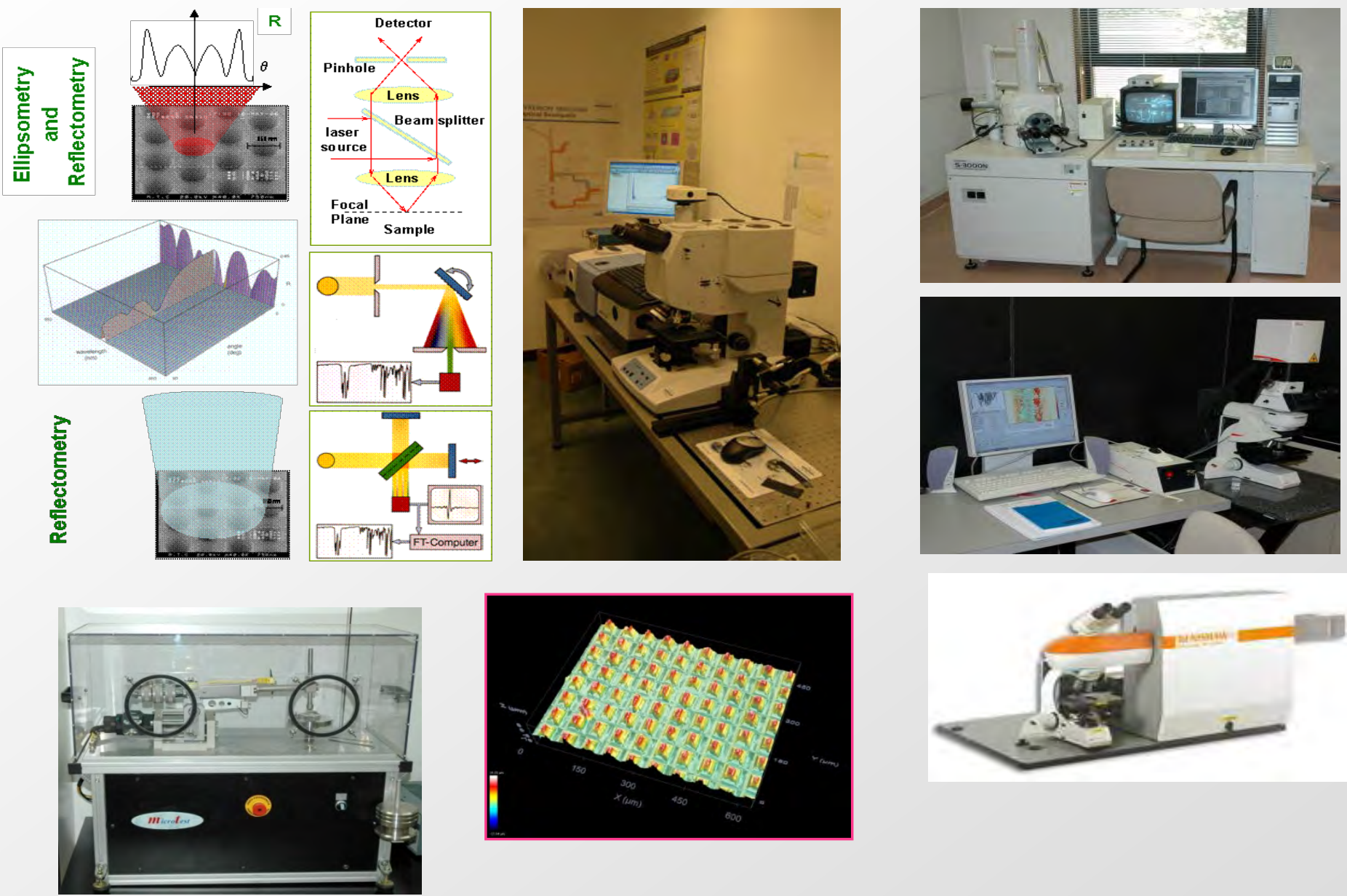

\section{CENTRO LÁSER}

UNIVERSIDAD POLITÉCNICA DE MADRID

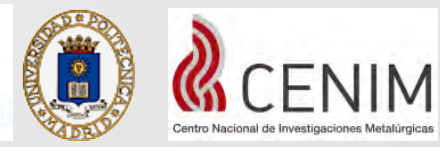

\section{International Conference on}

PROCESSING \& MANUFACTURING OF ADVANCED MATERIALS Processing, Fabrication, Properties, Applications 


\section{MICROMANUFACTURING EXPERIMENTAL SETUP AT CLUPM}
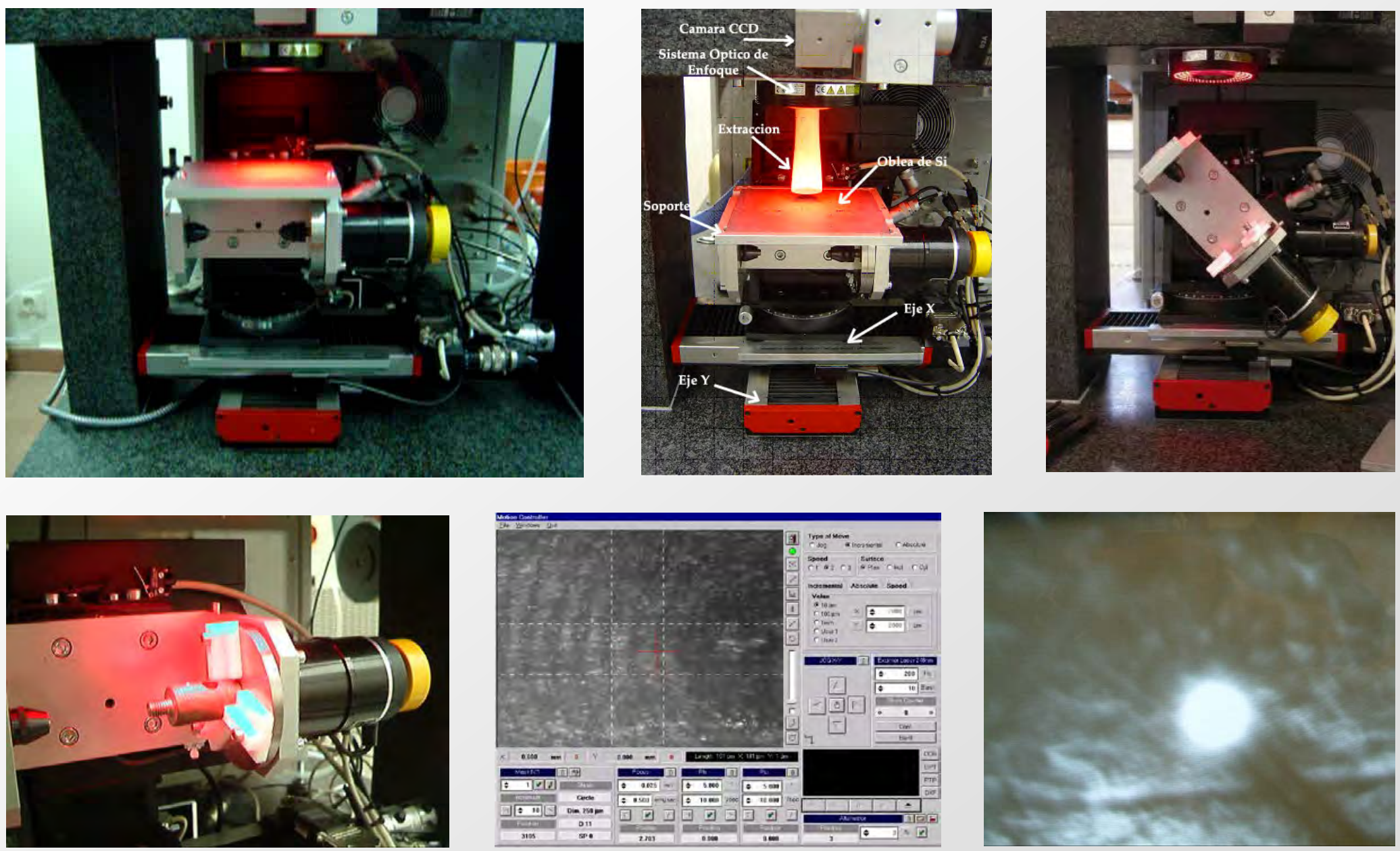

* CENTRO LÁSER

米 UNIVERSIDAD POLITÉCNICA DE MADRID

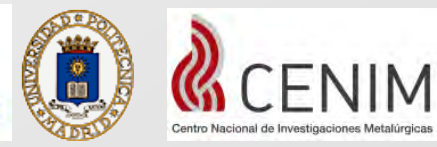

International Conference on

PROCESSING \& MANUFACTURING OF ADVANCED MATERIALS Processing, Fabrication, Properties, Applications 

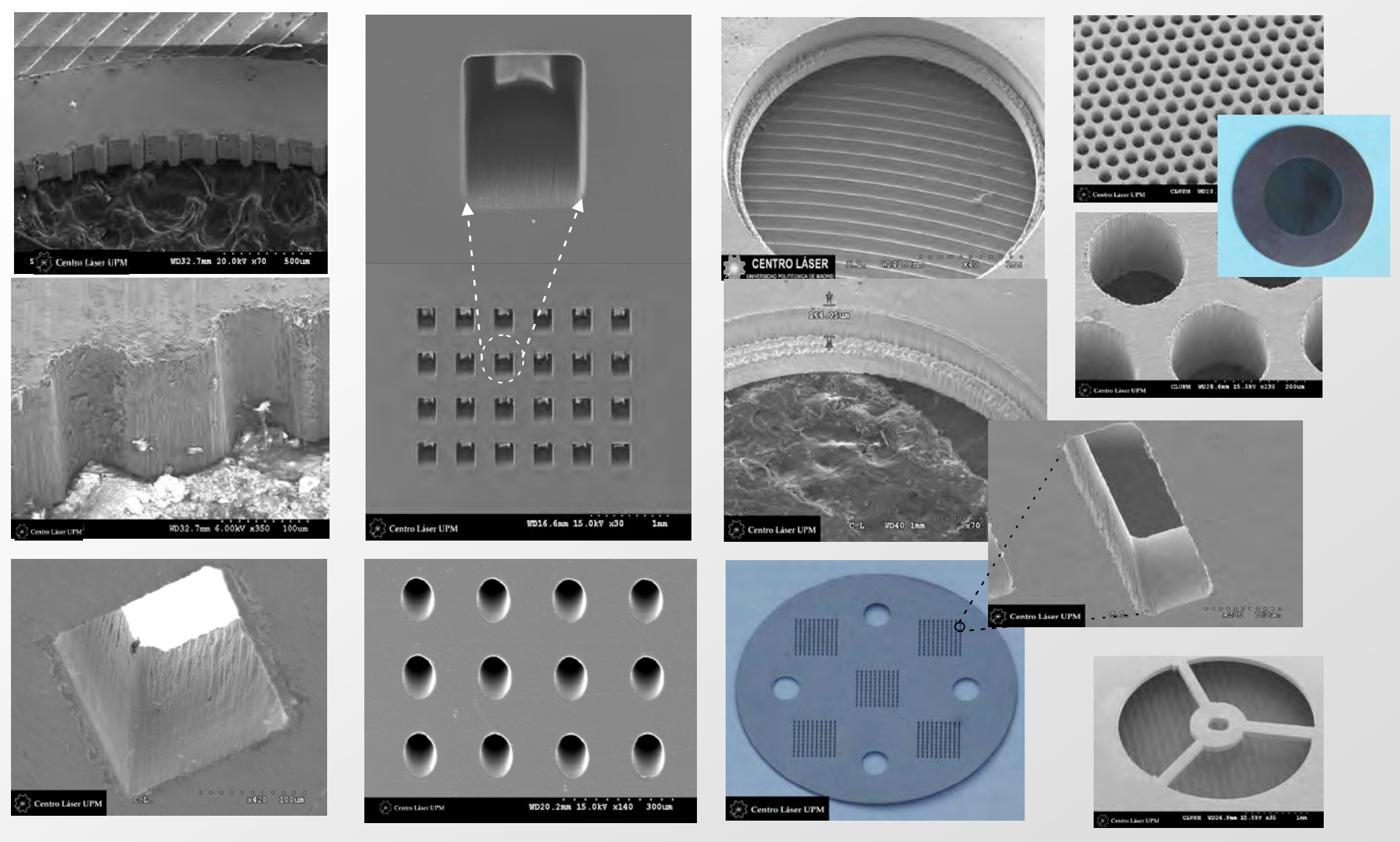

International Conference on PROCESSING \& MANUFACTURING OF ADVANCED MATERIALS Processing, Fabrication, Properties, Applications 

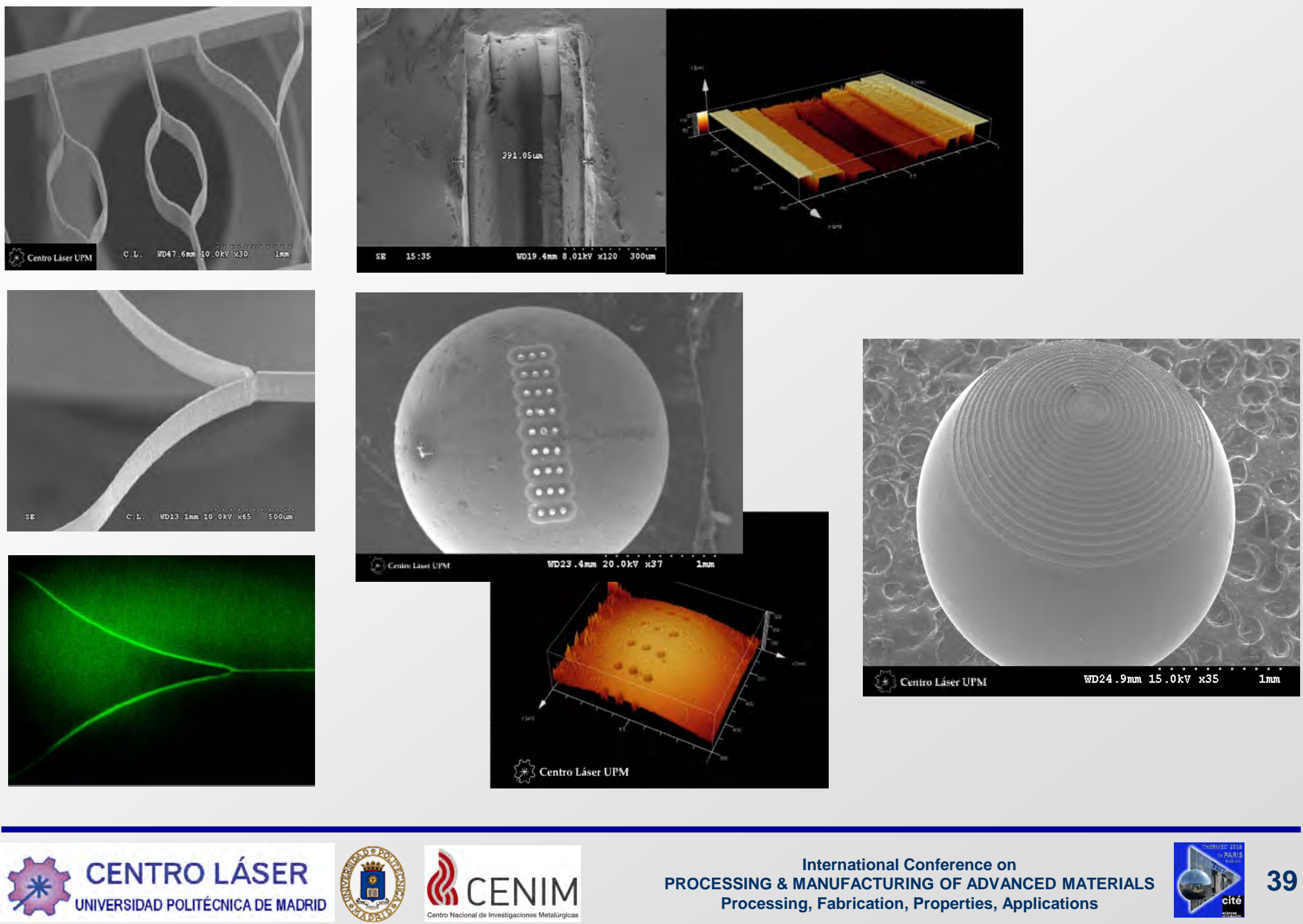

International Conference on PROCESSING \& MANUFACTURING OF ADVANCED MATERIALS Processing, Fabrication, Properties, Applications 

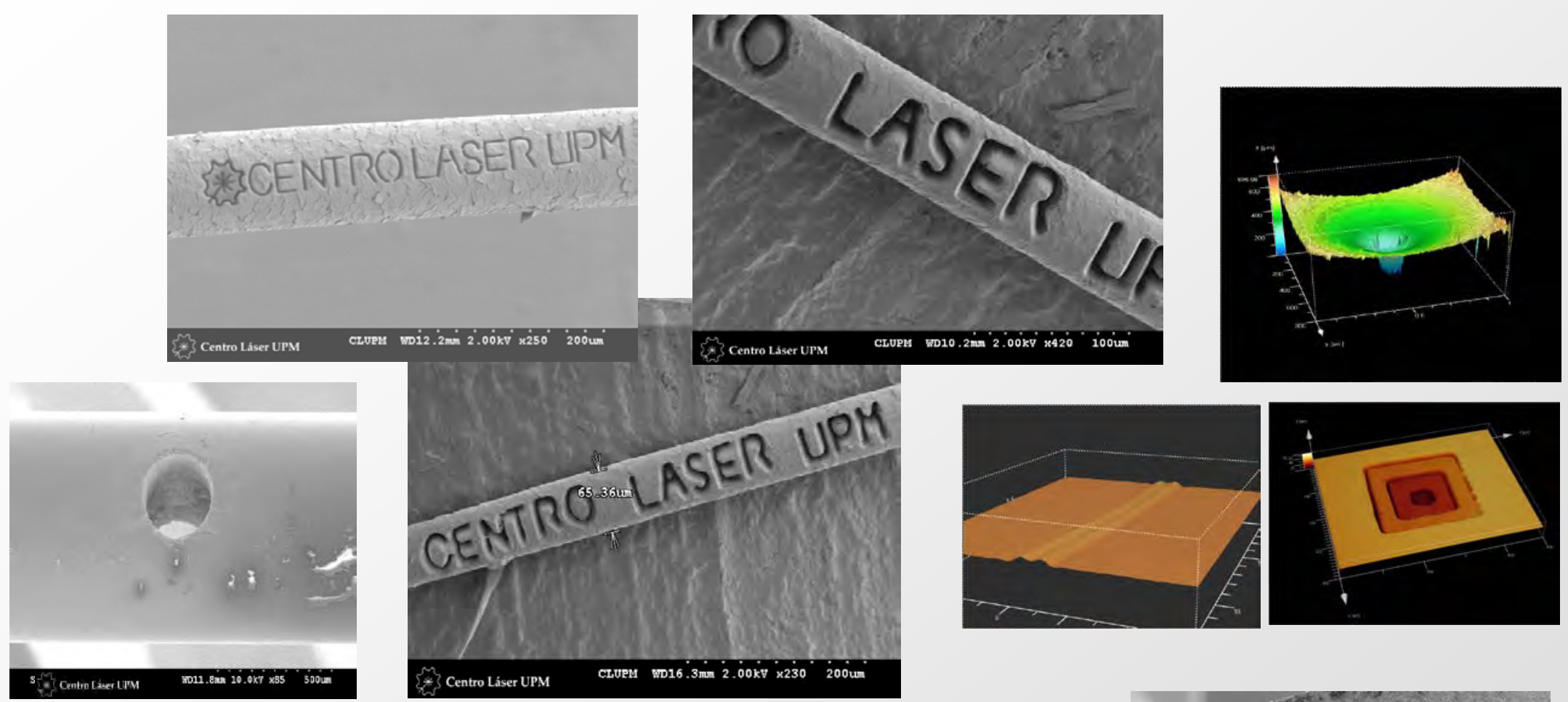

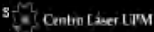

sol1. $\sin 10.0 \times 7 \times 655$ 500
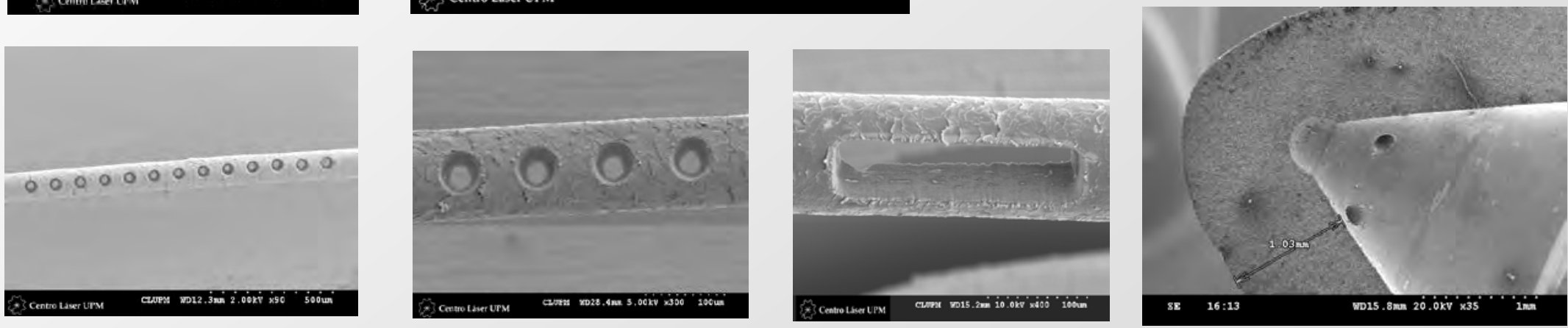

International Conference on PROCESSING \& MANUFACTURING OF ADVANCED MATERIALS Processing, Fabrication, Properties, Applications 

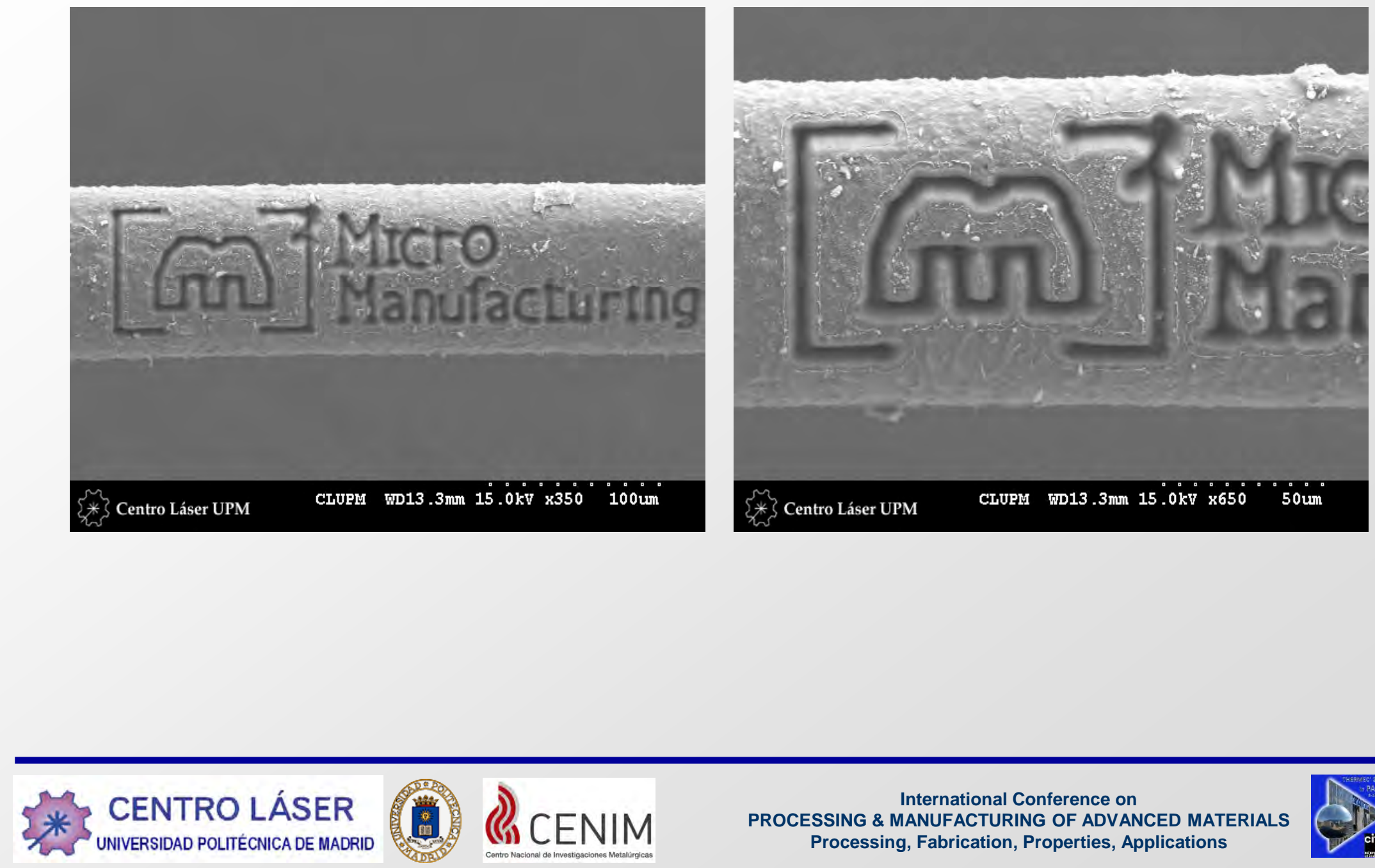
International Conference on PROCESSING \& MANUFACTURING OF ADVANCED MATERIALS Processing, Fabrication, Properties, Applications


$1000 \mathrm{fps}$

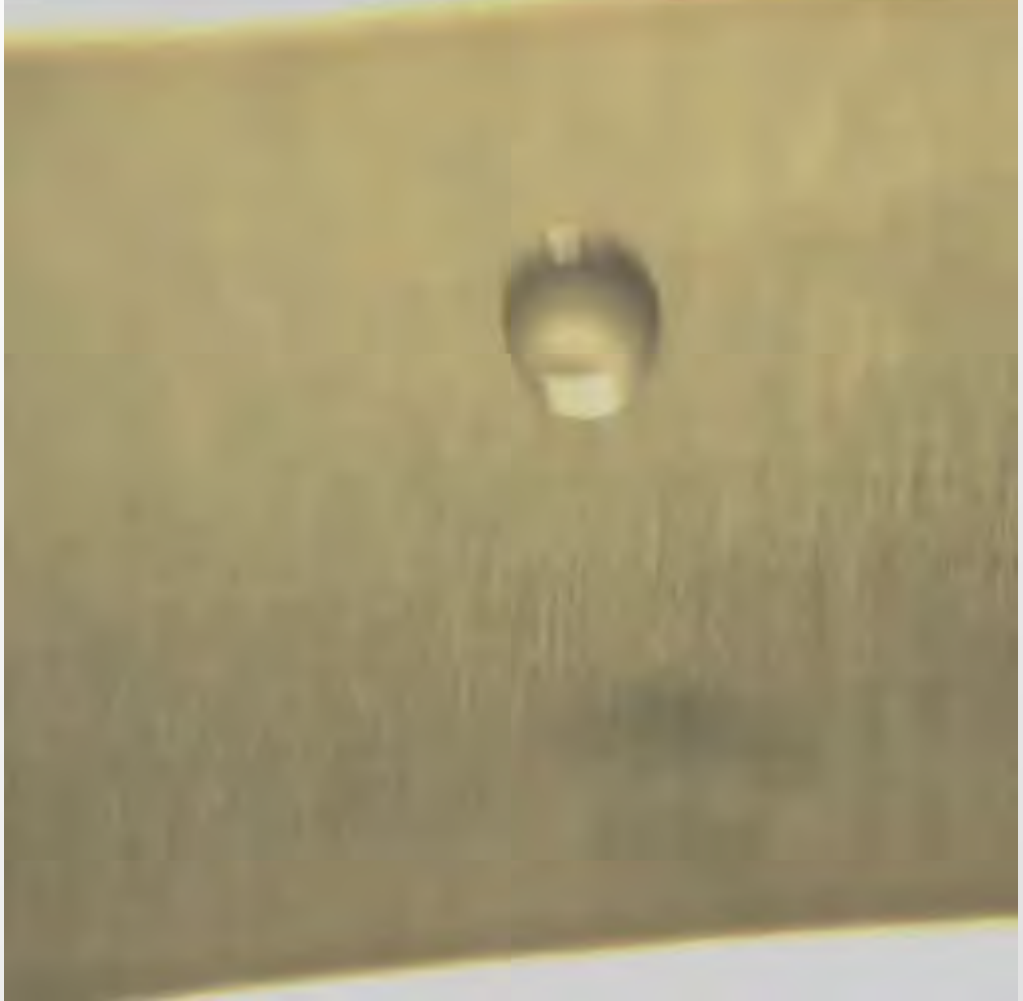


Photran

$500 \mathrm{fps}$

Start

FASTCHM-Ult ima512

$1 / 500 \mathrm{sec}$

frame : 363

$512 \times 512$

$+00: 00: 00.724000 \mathrm{sec}$

\section{CENTRO LÁSER}

UNIVERSIDAD POLITÉCNICA DE MADRID

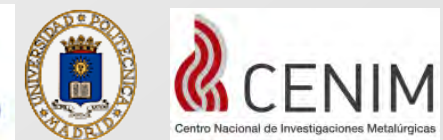

International Conference on PROCESSING \& MANUFACTURING OF ADVANCED MATERIALS Processing, Fabrication, Properties, Applications 


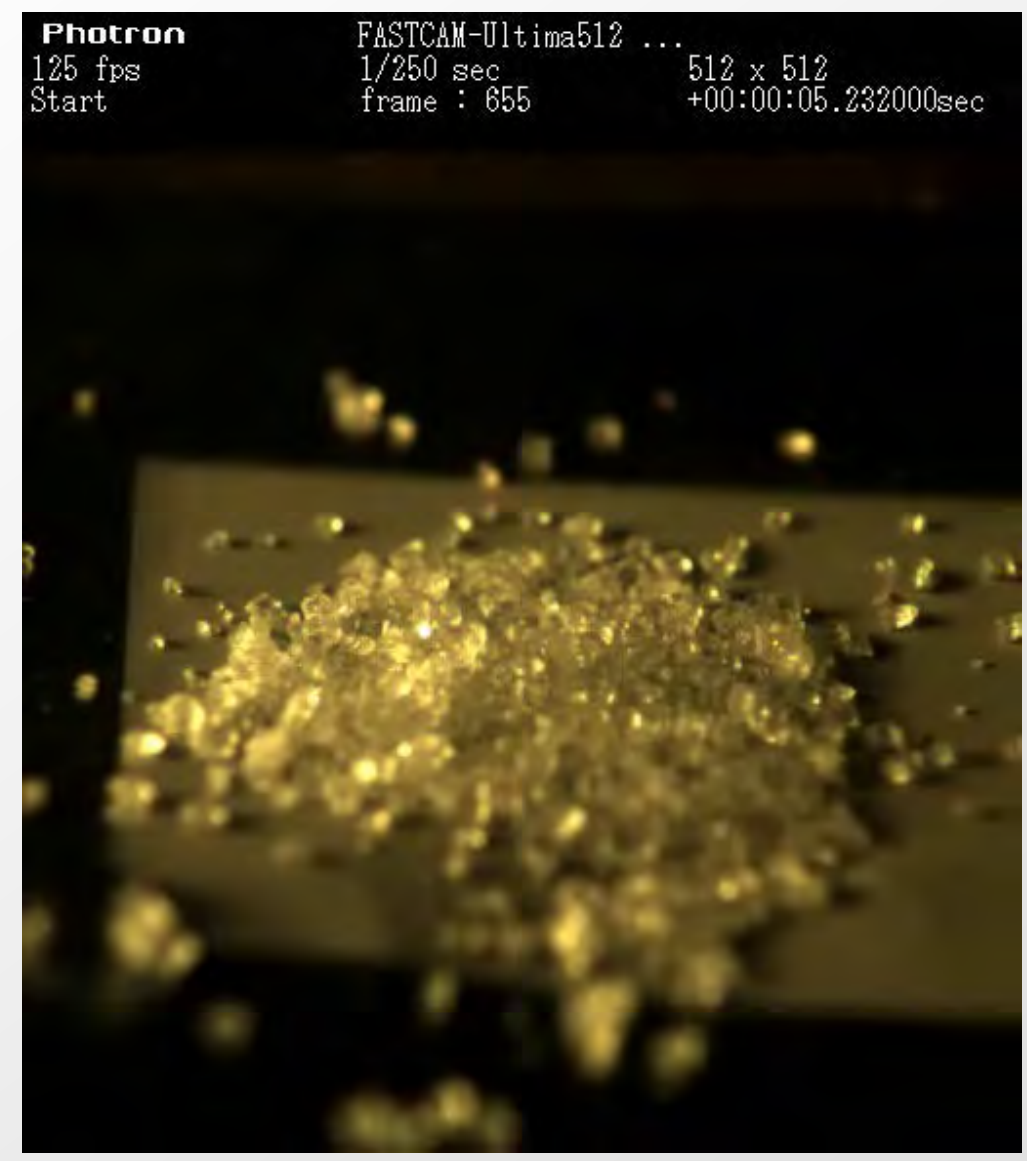

\section{CENTRO LÁSER}

(e) (l) CENIM

International Conference on PROCESSING \& MANUFACTURING OF ADVANCED MATERIALS Processing, Fabrication, Properties, Applications 


\section{The UPM Laser Centre Approach to LSP Development}

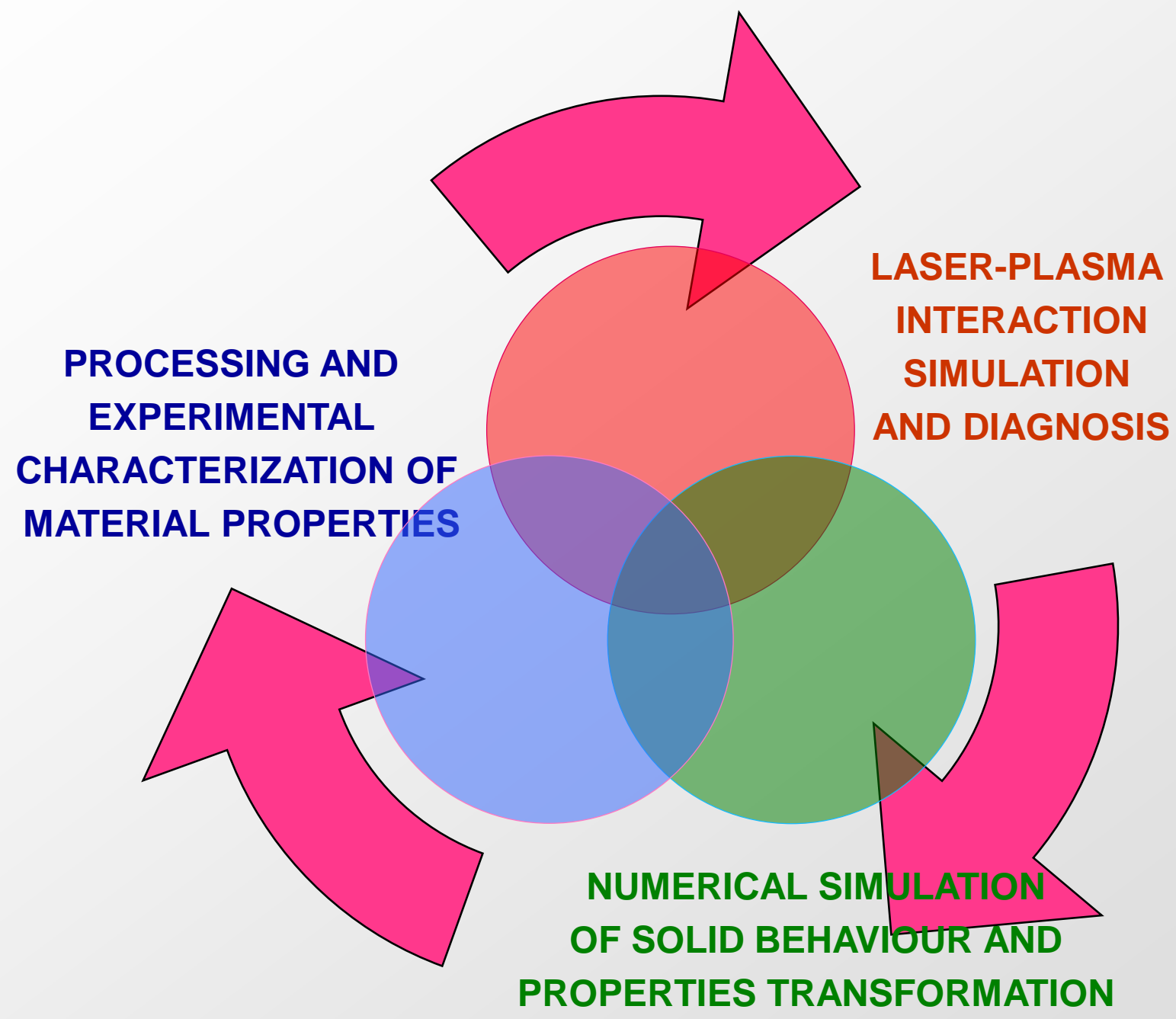

